\title{
INVISIBLES Y OLVIDADOS: INDIOS E INDEPENDENCIA DE BRASIL*
}

Julio Sánchez Gómez*

julio@usal.es

Resumen: El artículo trata de estudiar la relación de los indios de Brasil y la independencia del país considerada en el tiempo largo -1821-1850. Se aborda en él tanto a los indios como sujeto pasivo de la legislación, primero real, desde el tiempo de Pombal, pasando por el tiempo de la corte en Río y luego imperial, asi como de las discusiones parlamentarias y como sujeto activo en su actuación en las luchas independentistas.

Palabras-Clave: Brasil, indios, tiempo de Pombal, independencia, primer reinado, Regencia.

El presente volumen de las Visiones y revisiones de la independencia americana recoge una serie de contribuciones en torno a la participación - activa o pasiva - de los herederos de la población americana anterior al contacto con los europeos, los indios, en el proceso de independencia de América. Se revisa en ellas lo que ocurre en México, en los Andes, en Chile o en Paraguay. La situación en Brasil, que es el caso que me dispongo a abordar, difiere de forma sustancial de lo que ocurre en la mayoría de los territorios de antigua soberanía española. Fundamentalmente porque ni el peso ni la historia de las poblaciones indias ${ }^{2}$ en el mundo luso era igual que en una parte del hispano. No vivieron bajo la corona portuguesa grandes contingentes de agricultores sedentarios, de difícil movilidad, productores de excedentes, con una organización urbana desarrollada y sobre los cuales podía extenderse un cúmulo de impuestos y obligaciones. La población indígena brasileña estaba a la llegada de los portugueses fragmentada en

* Professor na Universidade de Salamanca. Professor visitante da UFG/Capes/2007. 
comunidades bien adaptadas a su ambiente concreto y dependientes en su inmensa mayoría de una economía de subsistencia de caza y recolección y en algunos casos de una agricultura de productividad incomparablemente menor que la de las grandes culturas andinas o mesoamericanas. Aun así, el papel de los indígenas brasileños en el proceso de la independencia de su país fue bastante más relevante que aquel que hasta hace muy poco se les había asignado, algo que entronca con el tratamiento que aquellos han recibido en general en la historiografía brasileña: el de figurantes mudos o víctimas pasivas de los procesos de carácter colonial y luego imperial en que se veían envueltos.

\section{HASTA EL TIEMPO DE LA INDEPENDENCIA}

Tan pronto se produjo la llegada de los europeos a la tierra de Brasil, las relaciones de los colonos con la población indígena fueron conflictivas. Desde las primeras décadas comenzaron a ser apresados y esclavizados y sus tierras a ser ocupadas para plantaciones. Ello provocó rebeliones y como consecuencia, guerra y muerte: expediciones de castigo y política de terror. La decisión inicial de la Corona de crear las "capitanías" llevaba unida la precisión de solucionar la necesidad de mano de obra de los capitanes donatarios: se les concedía el derecho a la adquisición y la venta de esclavos indios. Inicialmente, los esclavos eran prisioneros "rescatados" de las tribus enemigas, comprados con la justificación de que se les salvaba de la muerte por canibalismo. Y a medida que la economía se expandía y las necesidades de mano de obra se incrementaban, los sucesores de aquellos incitaban guerras intertribales a fin de obtener más prisioneros y, por tanto, más esclavos, antes de pasar a la esclavización violenta y sin disfraz.

La Corona portuguesa, ante la alarmante situación expidió las primeras regulaciones en torno a los naturales en 1548, incluidas en las Ordenanzas de 15 de diciembre de ese año expedidas por Pedro III al primer gobernador general de Brasil, Tomé de Souza (GOMES, 1988), una legislación que, si bien varió frecuentemente ${ }^{3}$ mantuvo dos constantes hasta la aparición de la pombalina a mediados del siglo XVIII: por un lado, la distinción entre los "indios mansos" o pacificados, que se convertían en vasallos de la corona bajo la tutela misionera en los denominados "aldeamentos", pueblos de indios, y que gozaban por ello de su protección y quedaba radicalmente prohibida su reducción a esclavitud y los "indios bravos", "tapuia" no sometidos y que manifestaban una actitud belicosa o puramente defensiva; respecto a éstos era 
lícito su sometimiento con cualquier medio bélico y su inmediata reducción a la esclavitud, en ese caso considerada justa.

La consecuencia fue una ambigüedad que permitió reducir a esclavos a importantes contingentes de indígenas mediante el simple procedimiento de argüir que habían mostrado actitudes hostiles o practicado la antropofagia ${ }^{4}$. Por otro lado, se permitía su utilización compulsiva como mano de obra, lo que permitía innúmeros abusos. Como se incentivaba también el manejo de indígenas como fuerza de choque en la lucha contra otros indígenas, por ejemplo de los tupís, para la defensa frente a las incursiones de los gê, mucho más belicosos.

La otra vertiente de la política indigenista portuguesa fue la entrega de la tutela ${ }^{5}$ de los indios a los religiosos, ratificada en el alvará de 1596, que concedía a los misioneros el poder de asentar y administrar los "aldeamentos", que aseguraban la conversión, la ocupación del territorio, su defensa y el suministro de mano de obra para las actividades productivas. Los padres sobre todo jesuitas - eran la autoridad en el plano espiritual, pero también en el temporal. Desempeñaron un papel ambiguo en la explotación de la mano de obra indígena. Si bien practicaban frecuentemente la obstrucción frente a la presión de los colonos para que les entregaran indios para el trabajo, al mismo tiempo utilizaron una gran cantidad de mano de obra indígena en sus propias explotaciones de azúcar o de tabaco. Los conflictos por la mano de obra fueron constantes entre colonos y padres, que se disputaban la dirección de las aldeas y el control de aquella. Como árbitro del conflicto, la corona portuguesa expedía órdenes - cartas regias, leyes, etc. - que compusieron una intrincadísima legislación, resultado de una política pendular que favorecía unas veces a la Compañía y otras a los colonos (ALARCON MEDEIROS, [200- b]; DOMÍNGUES, 2000).

En 1609, el rey declaraba libres tanto a los indios bautizados como a los que todavía son "gentiles conforme a sus ritos y ceremonias, los cuales todos serán tratados y tenidos como personas libres que son". Pero la reacción hostil y de amotinamiento de los colonos ante la ley - que alegaban, no solo la apremiante necesidad de brazos sin los que la colonia no sobreviviría, sino la imposibilidad de conseguir cristianización y civilización de los indios sin cautiverio - llevó, al igual que a la corona española con la encomienda más de medio siglo antes, a dar marcha atrás al monarca y a admitir nuevamente la esclavitud en "guerra justa" . Nuevamente la Corona volvió a reafirmar la libertad absoluta de los indios en $1680^{8}$ y en la legislación pombalina de 1755. En realidad la documentación regia relativa a indios manifiesta una preocupación por la falta de respeto de los colonos a 
las reglas que regían las aldeas, ya que de hecho mantenían a los habitantes más como siervos que como esclavos; la libertad era violada, el plazo estipulado para los trabajos - obligatoriamente remunerados, ya que se trataba de hombres libres - incumplido y los salarios, impagados. Al final, los indios de las aldeas, sobrecargados y explotados, estaban en peor situación que los esclavos (PERRONE-MOISES, 1992).

\section{EN TIEMPOS DE Pombal}

En 1755, el marqués de Pombal, el gran reformista ilustrado del dieciocho portugués, expidió dos decretos ${ }^{9}$ que supusieron un giro decisivo en la política portuguesa hacia los indios. El primero de ellos desposeía a los misioneros jesuitas de los poderes y las competencias de que habían disfrutado por delegación de la monarquía, el primer paso de la ofensiva contra la orden que culminaría con su expulsión cuatro años más tarde. Las funciones administrativas asignadas a los padres desde 1595 pasaban a ser ejercidas por directores legos y por los "juizes ordinarios, vereadores" y demás oficiales de justicia en las villas y por sus principales en las aldeas, es decir se establecía a partir de entonces una clara separación de las esferas de poder en los pueblos indígenas. El segundo, las llamadas "Leis de Liberdade", "libraron" a los indios de la legislación que permitía su esclavitud.

De un golpe quedaron anuladas las funciones políticas de los jesuitas, que funcionaban como mediadores únicos entre comunidades indígenas y Corona y su papel cultural en la configuración de la conciencia y la identidad indígenas (TREECE, 2008). Durante doscientos años la figura del misionero - esencialmente jesuita - acompañó al indio como una sombra, dirigiendo la incorporación de las comunidades tribales a la sociedad colonial, como volvería a hacerlo nuevamente - ahora en forma de capuchino - tras la instauración del imperio, que les devolvió su papel. Por tanto, el tiempo preindependencia y el de la separación fueron un paréntesis laico, una alternativa al sistema misional, entre dos periodos de cesión de la responsabilidad del Estado - colonial e imperial - a las órdenes regulares en relación con los indígenas.

La figura de los nuevos directores era la de representante de la autoridad real. Teóricamente, según explica el alvará real, se trataba de que los indios se autogobernaran y lo hicieran a través de sus propios "principales", pero "como éstos, por la lastimosa rusticidad e ignorancia con que fueron educados hasta ahora no tienen la necesaria aptitud que se requiere para el gobierno [...]", ante ello se creaba aquella figura, cuyas obligaciones consis- 
tían en convertir a los indígenas que aun no lo estuvieran a la fe cristiana, enseñarles la lengua portuguesa - abandonando de esa forma la hasta entonces omnipresente "lingua geral" ${ }^{10}$, que se consideraba que era un estorbo para "desterrar de los pueblos rústicos la barbaridad de sus antiguas costumbres"; el portugués era un instrumento de civilización ${ }^{11}$-, mantener el orden y contribuir a la introducción de las aldeas indígenas en la economía colonial mediante el incentivo a la agricultura destinada al mercado, a la cría de ganado y a la producción de excedentes comercializables, orientando el trabajo indígena al beneficio de la colectividad y no desviándolo al interés de particulares. No podían aquellos funcionarios ejercer jurisdicción sobre los indios, solo podían realizar labores de dirección, pues los encargados de aquella serían los jueces ordinarios y sus propios principales. Aunque los directores estaban encargados de proteger de abusos a los indígenas ${ }^{12}$, habitualmente se convertían en los grandes beneficiarios de la explotación del trabajo indígena, amén de apropiarse de una parte importante de la producción de la aldeia.

En el texto de la ley, un proyecto político alternativo al sistema de misiones, flotaba por un lado la confesión del fracaso de la política jesuítica para el objetivo de la Corona - que no era el mismo que el de los jesuitas - de hacer "útiles" a los indios y por otro la continuidad de la visión paternalista de la monarquía lusa ${ }^{13}$. Asomaba también algo que se convertirá en el tiempo de las discusiones constitucionales en un elemento central: la necesidad de hacer convivir a blancos e indios como uno de los medios civilizatorios: a este fin se incentivarían la instalación de blancos en los pueblos indios y los matrimonios mixtos ${ }^{14}$. Permeaba la legislación real el objetivo de convertir a los indios en vasallos del rey iguales a los lusobrasileños por medio de las órdenes de libertad y las medidas civilizadoras, así como lo más semejantes unos a otros a través del estímulo a la proximidad y la mezcla, aunque de momento se les consideraba todavía en estado de minoridad. El Directorio, en palabras de Moreira Neto era "un instrumento de intervención y de sumisión de las comunidades indígenas a los intereses del sistema colonial" y, según Ángela Domínguez (2000), también un medio de educación, destribalización y aculturación. $\mathrm{O}$ sea, una forma de convertir al indio, a quien ya se tenía formalmente concedido el estatuto de vasallo, un verdadero súbdito, un luso brasileño al servicio de los intereses de la corona, útil a la política colonial (DOMÍNGUES, 2000).

Bajo su retórica emancipadora, en la práctica, la nueva legislación, que mantenía prácticas extorsionadoras como los descimentos - agrupamientos - y la repartición de indios, principales medios de control de la 
fuerza de trabajo indio, supuso en el norte, la gran reserva de población indígena, la constitución de un gran reservorio de mano de obra asalariada y la proletarización de las grandes comunidades tribales indígenas, liberado el obstáculo que siempre suponían los jesuitas para la directa relación de los colonos con los indios y con el auxilio de sus principales, convertidos en agentes estatales para el aprovechamiento de la fuerza de trabajo ${ }^{15}$. Aun cuando teóricamente se trataba de relaciones entre empleadores y asalariados - la pretensión del Directorio era que con la introducción de factores como excedentes, salarios, riqueza y lucro, el trabajo pasara por sí mismo de compulsivo a voluntario - en la práctica las condiciones estaban muy lejos de ser liberales: los salarios estaban muy por debajo del nivel medio, y las condiciones de explotación eran durísimas resultando en jornadas de trabajo de más de diez horas que acarreaban altas tasas de mortalidad ${ }^{16}$. La consecuencia final, a la que se unió la corrupción de la mayoría de los directores, fue desintegración y marginalización. Sin preparación para competir con el resto de la población, las comunidades acabaron transformandose en una masa expropiada y separada, tanto de los propios indígenas tribales aislados como de la población rural blanca. Esos indios destribalizados formaron una gran reserva de mano de obra, pero con un gran potencial de descontento que estallaría, como veremos, en la denominada Cabanagem en 1830.

\section{LOS INDIOS EN EL TIEMPO DE LA INDEPENDENCIA}

\section{La Política Hacia el Indigena de la Corte en Brasil}

Inmediatamente antes de la llegada de los Bragança a sus posesiones de ultramar se habían producido importantes modificaciones en la legislación que regulaba la vida de las poblaciones indígenas. En el marco de la revisión a que fue sometida la legislación y la política pombalina durante el reinado de Maria I, en 1798 quedaba revocado el Directorio de 1755-1757, si bien continuó en vigor de facto hasta bien entrado el tiempo imperial, a causa de las lagunas legislativas que solo fueron solucionadas con el Reglamento de Indios de 1845, que vuelve a reafirmar la figura del Director de aldea, mientras que los misioneros vuelven nuevamente a primer plano como instancia organizativa.

Estas actuaciones continuaron tras la llegada de la corte a Brasil, que supuso incluso una acentuación de la política agresiva - una auténtica licencia de "caza al indio" - de la monarquía frente a los pueblos nativos. La práctica de la Corona en ultramar fue de hecho un programa de exterminio renovado 
frente a los pueblos considerados insumisos, al tiempo que se procuraba la sumisión - "domesticación" - y conversión en "mansos" de aquellos que se sometieran ${ }^{17}$, política que se prolongaría durante todo el tiempo de la corte en la colonia. La carta regia de 1798, fruto de la presión de los hacendados, insatisfechos con la forma "branda" con que los indios eran tratados y partidarios de sustituirla por violencia con el fin de liberar territorios y conseguir mano de obra forzada, fue el primero de una serie de decretos que ordenaron campañas militares en forma de "guerras justas" contra grupos específicos de indios a los que se consideraba "incapaces de civilización"; etnias que habitaban en Bahia y Sao Paulo, botocudos ${ }^{18}$ de Minas Gerais, timbiras de Maranhao..; todos ellos fueron objeto de formas particularmente crueles de exterminio, como la introducción de enfermedades, el reconocimiento de la figura del "caçador de indios", la utilización de grupos de éstos - indios mansos - en la lucha contra otros indígenas o la entrega de los prisioneros nativos a sus captores como esclavos por largos períodos de hasta quince años, en una larga campaña que se prolongó desde 1798 hasta el fin del primer reinado de la independencia en 1831.

La política de la corona abrió la puerta a la actuación hostil de los particulares, autorizando a organizar bandeiras e incentivados con la recompensa de tierras y siervos indígenas. Los choques entre blancos e indígenas por el uso de tierras, el temor de aquellos a éstos y las acusaciones de agresión y consiguiente petición de licencia para lo que consideraban defensa, llenan los archivos en la documentación de aquellos años ${ }^{19}$. La ocupación de tierras estaba siempre en el centro de los ataques a los indígenas: por ejemplo, la Carta Regia de 5 de mayo de 1801, decretaba "guerra ofensiva aos botocudos antropófagos (!!)" y era clara continuación de la que dos meses antes, el 6 de marzo del mismo año permitía la distribución de tierras en las márgenes de los ríos dónde aquellos indios se asentaban. Además, la región de los botocudos era central en el desarrollo de las regiones de Bahía y Minas porque estaba en el camino entre ambas capitanías (PARAISO, 1992) ${ }^{20}$.

Paradójicamente, la política agresiva en la práctica coexistía con la idealización del indio en el imaginario cortesano. En las numerosas fiestas y solemnidades que tuvieron lugar desde el desembarco de la familia real hasta su reembarco trece años después, la representación simbólica de Brasil era siempre ostentada por un indio (LUCCOCK, 2005). ${ }^{21} \mathrm{Y}$ es que los años de la consolidación del Estado-nación en Brasil, desde fines del siglo XVIII hasta el último cuarto del XIX fueron los de un movimiento intelectual, el más coherente, durable e influyente antes del modernismo: el indianismo, que, a la llegada de la corte a Río había producido ya tres poemas épicos 
de exaltación del indio ${ }^{22}$. Nacía así una cruel paradoja, a decir de David Treece (2008):

en cuanto protagonista heroico de innumerables romances, poemas, piezas teatrales, pinturas y estudios etnográficos, lamentado o celebrado, como exiliado, aliado o rebelde, el indio vino a hacer corpóreo aquel mismo nacionalismo que se empeñaba en llevar a cabo su propia aniquilación (TREECE, 2008)

Casi de forma inmediata tras su llegada a ultramar, el todavía Príncipe Regente expedía nueva carta regia - 13 de mayo de 1808 - en que volvía a reafirmarse la autorización para hacer "guerra justa" contra los "botocudos" y contra los bugres de Sao Paulo ${ }^{23}$, a la que se añadían otras contra los timbira de Maranhao o los coroados de Paraná, o la que en 1811 la extendía también a los xavante, karajá, apinayé y canoeiros (LOPES DA SILVA, 1992) habitantes del territorio de Goiás, mientras que declaraba vacías y dispuestas para su ocupación las tierras conquistadas en tales guerras, lo que abrió un verdadero proceso de terror entre las poblaciones nativas. Tristemente, una de las primeras medidas del soberano en su nueva sede fue hacerle la guerra a una parte de sus súbditos.

\section{Indios y DISCUSión CONSTITUCIONAL En PORTUgal}

No fueron muchas las intervenciones que se produjeron en relación con los indios de Brasil, ni en las Cortes Constituyentes, ni, aun menos, en las posteriores legislativas. La problemática suscitada por los indios resultaba menor para unos diputados enfrentados a dificultades tan considerables como la creación de un nuevo orden político que provocaba fuertes disensiones en el interior, la hostilidad de la Santa Alianza en el exterior y poco más tarde la creciente conciencia del peligro de separación de Brasil. En las Cortes Constituyentes fueron cinco los proyectos presentados en relación con ellos, todos por ciudadanos de origen brasileño, unos diputados y otros no.

Los indios no aparecen en la magna asamblea hasta el 18 de mayo de 1821 , cuando las Cortes llevaban ya reunidas cuatro meses ${ }^{24}$. Se discutía ese día un asunto muy relevante: la religión de la nación portuguesa ${ }^{25}$. Se consideraba la posición de las religiones no católicas: tolerancia o no. El diputado Trigoso se opone a la tolerancia y defiende solo la existencia de garantías para que los extranjeros puedan practicar sus creencias sin ser perseguidos por ello. Pone como ejemplo de súbditos que no pertenecen a la religión que 
él denomina "nacional" a los indios americanos y cómo frente a ellos no se ejerce la tolerancia respecto a sus creencias, ya que;

Los indios deben ser catequizados y mientras sean sujetos al imperio portugués, la constitución misma en el artículo 180 manda proveer a su conversión y civilización. Los españoles tienen indios en sus Américas y a pesar de esto, los españoles decretaron que la Religión católica y apostólica y romana era la única del país (DIÁRIO DAS CORTES..., 1821a).

El diputado Correa de Seabra se opone también a la institucionalización de la tolerancia religiosa y prefiere trasladar ésta a los tratados bilaterales con los países que practican mayoritariamente otras religiones. Correa de Seabra, frente a los que objetan que no solo hay extranjeros, también hay ciudadanos portugueses que son gentiles, por ejemplo, los indios americanos súbditos de la Corona - recordémoslo, reconocidos así - va más allá de lo que iba Trigoso; niega la calidad de ciudadanos a los indígenas, a los que la legislación del Antiguo Régimen sí concedía la de vasallos de la Corona en igualdad de condiciones con todos los demás vasallos. Decía Correia de Andrade (1965):

Veo objetar contra esto [la exclusión de la tolerancia] que nosotros de hecho tenemos en los Estados Ultramarinos ciudadanos que son gentiles y que no debemos ahora por esta cláusula de la Constitución excluirlos de nuestra sociedad, sin embargo no reconozco por ciudadanos portugueses a los tapuias bravíos de Brasil, o a los gentiles de la Costa de Africa, tenemos cuando mucho una cierta dominación sobre los que están aldeados, que solo dura cuanto ellos quieren. Y si se habla de esta desgraciada gente debe ser solo por acordarnos de cuidar con todo el celo en catequizarlos y tratarlos con toda humanidad (ANDRADE, 1965).

$\mathrm{Y}$ es que solo la religión podrá en un momento posterior elevarlos a la condición de ciudadanos:

Solo ella, [la religión católica] enseñada por ministros píos y celosos es quien ha podido sacar de la barbarie a los tapuias y africanos que se han civilizado y podrá civilizar al resto si en eso se pone el debido cuidado. No es con tolerancia sino con la enseñanza de la religión que tenemos que habilitarlos para ser ciudadanos portugueses porque solo así los podemos poner en estado de civilización, sin lo que no pueden hacer parte de una sociedad 
civil en que haya ideas de justicia, amor a la patria y obediencia a las leyes (ANDRADE, 1965).

El interés por la catequización de los indios y el papel que se confiaba en la asimilación a las órdenes religiosas aparece claro en el proyecto presentado por la Comisión Eclesiástica de Reforma, datado en 1822, cuyo artículo 12 preveía el mantenimiento de centros, tanto en Brasil como en la metrópoli cuyo fin era formar misioneros para la catequización de los indios. ${ }^{1}$

Casi inmediatamente después de la toma de posesión de los primeros diputados brasileños, el 10 de septiembre de $1821^{2}$, un ciudadano paraense, José Caetano Ribeiro da Cunha, de Pará, presentaba una memoria titulada Memoria Analítica y Demostrativa Del Sistema, Conducta y Administración de los Indios en General de la Provincia de Grao-Pará e Intereses que Pueden Resultar, Ofrecida al Congreso por el Ciudadano José Caetano Ribeiro da Cunha, un texto de queja en torno a la pobre condición de la provincia y las dificultades para conseguir mano de obra india.

El 18 de marzo de 1822 tenía entrada en la asamblea una propuesta de decreto del diputado bahiano Domingos Borges de Barros ${ }^{3}$. Su proyecto - que constaba de 30 secciones, de las que doce se ocupaban de los indios y las demás, de la colonización europea y la esclavitud negra y que apareció impreso en el Diario das Cortes - se orientaba sobre todo al poblamiento del territorio del Brasil, para lo que se dirigía a dos tipos de posibles pobladores: emigrantes europeos e indios. A fin de organizar el dispositivo poblacional, proponía la formación en cada provincia de Brasil de Juntas que, en relación con la población indígena tendría como fin la eterna idea de "aldear e civilizar os indígenas", mediante su concentración en poblaciones. Su propuesta era sobre todo, un proyecto de colonización territorial y sus ideas en torno a los indígenas estaban dirigidas a convertirlos en agentes de su idea de colonizar y valorizar el territorio.

Proponía Barros mantener como legislación básica para regir la vida de los indios el Directorio Pombalino, del que se exceptuarían los artículos - 27 al 34 - referentes a la obligación del pago del diezmo, del que quedarían exentos por seis años, y a la entrega a los directores de una parte - la sexta de los frutos recolectados en las aldeias y aquellos que organizaban el trabajo obligatorio de los indios en las tierras de los colonos de la zona - artículos 56 a 70 -; en lo sucesivo serían libres para trabajar allí y cuando lo desearan. A las nuevas poblaciones de indios que se fundaran se les otorgarían tierras y se pondría a su frente a un director civil que debía ser "de buenas costumbres y 
dulzura de carácter", mientras que su cristianización, que ocupaba un lugar central en el proyecto, se entregaría a los hermanos moravos, para lo que se les haría llegar desde Europa. Es esta una insólita propuesta en el marco de un país de oficialidad estrictamente católica.

A fin de hacer atractivo el asentamiento de indios se entregarían, con las correspondientes parcelas de tierra, el capital suficiente para ponerlas en labor, instrumentos agrícolas y ayuda para levantar una casa; las costumbres ancestrales de las comunidades se respetarían y se destinarían determinadas fechas para su práctica ${ }^{4}$. Cada aldea debía convertirse en foco de atracción para los "indios errantes", atrayéndolos por medio del comercio y enseñándoles medios de vida ${ }^{5}$. Para ese proceso de aldeamento procurará implicarse a los particulares, incentivándolos por medio de premios ${ }^{6}$. En su proyecto plantea por primera vez la cuestión de la ciudadanía de los indios, que luego será objeto de discusión en los debates constitucionales y la asocia - junto con la de los gitanos - a la propiedad o a la actividad económica ${ }^{7}$.

La propuesta del diputado bahiano fue el pistoletazo de salida para la presentación subsiguiente de varias propuestas relacionadas con la población aborigen. El uno de abril era un diputado pernambucano, Francisco Moniz Tavares ${ }^{8}$, quien entregaba una moción dirigida nuevamente $a$ "la civilización de los indígenas de los sertôes de Ceará, Minas Geraes y Mato Grosso”. El leit motiv de la asimilación permeaba éste proyecto como lo hacía el anterior, con estricta recomendación del uso de procedimientos "suaves y persuasivos", además de aconsejar que se siguieran en Brasil las prácticas seguidas por William Penn y otros americanos del norte 9 .

Nueve días después, el 9 de abril era nuevamente un ciudadano, Enrique Guilherme Smith, quien hacía entrar una memoria para su discusión en la asamblea sobre la inmigración y la colonización por medio de los indios (DIÁRIO DAS CORTES..., de 1822c). El 6 de mayo siguiente, el diputado por Pará, obispo Romualdo de Souza Coeho (apud DIÁRIO DAS CORTES ..., 1822e $)^{10}$ presentaba un proyecto destinado al "progreso y mejoramiento de aquella provincia [la de Pará, a la que él representaba], que siendo sin contradicción la más rica del Brasil, se encuentra desgraciadamente como la más atrasada" y en la que la población nativa representaba un peso en términos tanto absolutos como porcentuales mayor que en ninguna otra de Brasil ${ }^{11}$. Entre otras providencias exponía la necesidad de dividir la inmensa diócesis de Pará en dos: Pará y Río Negro, dada la imposibilidad de atender desde Belem el inabarcable territorio. La razón fundamental para esa partición sería 
nuevamente la cristianización de los indios y su mejor aprovechamiento en el desarrollo de la economía del territorio:

la decadencia sucesiva de aquella capitanía procede de la falta de sacerdotes que el obispo de Pará no puede remediar. Sólo pues con este arbitrio se podrá, no solo acelerar la civilización de aquellos pueblos, sino también arrancar de la garras del paganismo inmensas familias de indios que habitan aquellos bosques $y$, siendo bien dirigidos, aumentará la prosperidad nacional con más ventaja que con los negros africanos, marcados con el sello de la esclavitud (El DIÁRIO DAS CORTES, 1822).

En alguna ocasión fueron los propios indios quienes, de forma colectiva, se dirigieron a la Asamblea Constituyente en demanda de derechos conculcados o en petición de modificaciones en su status. En la sesión del 18 de diciembre de 1821, casi un año después de la puesta en marcha de las discusiones parlamentarias de las Cortes constituyentes, llegaba a ellas la voz de los propios indios. En esa ocasión quienes presentaban una representación eran los "principales de los indios y gentíos de las cinco naciones [sic] unidas" de las márgenes del río Tocantins y fuentes del río Guajalú, Turi y Gurupi, en los límites de las provincias de Minas, Maranhao y Pará. Su petición hacía referencia a la legislación pombalina, cuyas prescripciones pedían que se cumplieran - "providencias a favor de la propagación de la religión, de la restitución de la libertad de sus personas, de sus bienes y de su comercio" - y, sobre todo, reclamaban que se les delimitara su territorio respecto a la provincia de Pará para evitar que continuaran las reiteradas invasiones. Pedían también que se les edificara "una población grande y en ella un majestuoso templo dedicado a San Juan Bautista”. Más allá de las demandas en sí, que buscaban la protección del Estado, ahora encarnado en las lejanas Cortes, la petición revelaba, como sucedería repetidamente a lo largo del tiempo imperial, la capacidad de autodefensa en el terreno legal de muchas comunidades indias y la existencia e importancia de autoridades reconocidas entre ellos. La comisión correspondiente de la asamblea, que discutió solo sumariamente la petición, trasladó al gobierno la orden de hacer cumplir la legislación - concretamente recordaba el Directorio de 1757, legalmente derogado en 1798 - en aquello que se refería a la civilización y conversión de los indios. En cuanto al deslinde de territorio, la comisión argüía carencia de información para no pronunciarse y dejaba a las Juntas de Gobierno que habían de constituirse inmediatamente en Brasil - en este caso las de 
Pará, Maranhao y Minas Geraes - , que fueran ellas las que informaran al gobierno para que éste tomara decisiones en orden a

establecer un sistema el más liberal y ajustado a las circunstancias de cada provincia, de dónde puedan sacarse ventajas para la civilización de los indígenas de aquel vasto continente [...], a fin de que los beneficios de nuestra regeneración política alcancen a los aborígenes de una tan importante parte del Reino Unido DIARIO DAS CORTES..., 1821b.

Otros conflictos protagonizados, o de los que eran víctimas los indios, llegaron a oídos de las Cortes constituyentes: el veintinueve de abril de 1822, la Junta de Gobierno de Río Grande do Norte remitía a la asamblea lisboeta una queja que le había llegado, presentada por los indios y otros moradores del pueblo de Estremoz, en el que se quejaban del proceder de su párroco ${ }^{12}$. La comisión de Cortes la remitió al gobierno para que tomara medidas.

Pero la única propuesta que logró retener la atención de los constituyentes fue la de Francisco Ricardo Zany, italiano de nacimiento, paraense de residencia y militar al servicio de Portugal primero y de Brasil después y que desempeñó trabajos para la administración de aquella provincia (DIARIO DAS CORTES..., 1822j). A Zany le preocupaba la potencialidad desaprovechada de la comarca amazónica de Río Negro en Pará, un territorio en el que la inmensa mayoría de la población estaba formada por indios y los mestizos de blancos e indios allí llamados mamelucos. Por tanto, el desarrollo económico de la comarca solo sería posible con la introducción de los indios por medio de la formación de aldeas en la vida común.

A fin de conseguir la utilidad de los indios, en definitiva la verdadera pretensión de la propuesta de Zany, proponía éste la erección - en la comarca amazónica - de una administración de indios formada por delegados locales de un inspector general de la provincia, cuya principal misión era vigilar la adecuada cristianización de aquellos. Los indios perdían su libertad de movimiento y aquellos serían los administradores de la fuerza de trabajo remunerada - de los indígenas. Aquellos labradores para quienes trabajaran los indígenas se obligaban a educarlos y cristianizarlos y el tiempo máximo de enganche de los indios sería de seis años.

\section{La Propuesta de José Bonifacio para la Integración de los Indios}

José Bonifacio de Andrada e Silva, un hombre polémico para la historiografía, que ha sido reputado por una parte de conservador y de ser uno de 
los pilares que marcó el carácter casi reaccionario que tuvo la independencia de Brasil, mientras que para otra parte de aquella fue el paradigma del reformismo radical ${ }^{13}$. Ministro do Imperio y de Negocios Extranjeros, "Patriarca de la Independencia" y tutor de la minoridad de Pedro II, su biografía es sobradamente conocida y solo tendremos en cuenta aquí su propuesta en relación con los indios dirigida a las Cortes lisboetas y luego reiterada con muy ligeras variantes a la Assembleia Constituínte do Imperio do Brasil con la intención de que fuese la base de un "regimiento general para la catequización y civilización de los indios que debe cuanto antes formar el Poder Legislativo" (ANDRADA, 2005) ${ }^{14}$.

Si bien las ideas expresadas por Andrada no tuvieron demasiado eco en las asambleas a las que se dirigió, fueron la referencia más inmediata y constante de las políticas indigenistas del siglo XIX y pervivieron suficiente tiempo como para ser reivindicadas cien años más tarde, en 1910, al inaugurarse la institución central que la República dedicaba a la atención de la población india, el Serviço de Proteção aos Índios. Su primer director, el célebre Cândido Mariano da Silva Rondon declaraba "aceptar las ideas, los procesos y las medidas aconsejadas por el Patriarca en su proyecto sobre la civilización de los indios".

Los "Apontamentos", presentados a la Asamblea en $18222^{15}$ parten de una premisa: en la hora de la emancipación nacional no hay libertad sin la libertad de todo el pueblo y para ello plantea dos proyectos: el de incorporación del indio a la sociedad nacional y paralelamente la emancipación gradual de los esclavos ${ }^{16}$ para que ambos, indios y negros libres puedan convertirse en ciudadanos de la nueva patria. No es, por tanto, a diferencia de otros proyectos aparecidos en el mismo tiempo, una propuesta aislada. Es parte de un proyecto de constitución de una nueva sociedad civil para el imperio. Un espacio que era preciso poblar y para ello se contaba con portugueses, indios y esclavos importados.

El plan de Bonifacio partía de una crítica radical de la política colonial opresora de Portugal ${ }^{17}$, que era preciso superar con otra más "esclarecida" y que uniría la problemática indígena con la de la esclavitud negra: la solución al problema indio convertiría a ésta en innecesaria y, por tanto, debería ser - gradualmente - eliminada.

EL horizonte del patriarca era el de viabilizar la nación. Su diagnóstico sobre Brasil era negativo. El brasileño, por naturaleza, por clima y por herencia colonial era perezoso, indolente e ignorante ${ }^{18}$. Pero si se adoptaba una política reformista correcta, el cuadro se podía mejorar sustancialmente y los enemigos seculares - blancos propietarios, negros esclavos, indios 
salvajes - convertirse en compatriotas y conciudadanos. Pero cualquier educación seria estéril si antes de nada la heterogénea población brasileña no se trasformaba en un conjunto homogéneo en todos los sentidos: racial, cultural, legal y cívico. Lo que hoy llamaríamos "diversidad cultural" es algo que debe ser desterrado en pro del mestizaje y la uniformidad cultural. Solo así aparecería una verdadera identidad nacional.

Para los indios, lo que se proponía era un programa a medio plazo integracionista, de contacto progresivo con la población blanca ${ }^{19}$ y de dignificación, con nuevos "aldeamentos" de los nativos, empleando procedimientos pacíficos y no coercitivos. Bonifacio ponía mucho énfasis en la educación y en el estímulo a los matrimonios entre indios, blancos, negros y mulato ${ }^{20}$. Porque para el futuro ministro, pensador radicalmente imbuido de la ilustración, todos los hombres nacían iguales y dotados de la misma capacidad racional; las diferencias entre unos y otros provenían de las contingencias socioculturales y ambientales ${ }^{21}$. Por tanto, indios y africanos eran perfectamente asimilables en la futura sociedad brasileña. El ideal de la sociedad brasileña para Bonifacio era la sociedad "misturada", mestiza; hacer de todos ellos un solo cuerpo de nación. El mestizaje sería la forma de amortiguación de los problemas que incubaba la sociedad en su estado actual.

Y para llegar a la incorporación de los indios era imprescindible su conversión a las nociones civilizadoras de propiedad, trabajo ${ }^{22}$ - trabajo voluntario; los indios mansos son libres -, agricultura, religión, matrimonio, gobierno, etc.; conseguir tales objetivos requería cesar todo tipo de guerra y violencia contra ellos y reconocer que el trato que habían recibido era el peor imaginable, incluido "el continuo robo de sus mejores tierras". Con las nuevas aldeas que los indios formaran y su aplicación a la agricultura podrían aumentar los cultivos y enriquecer así la producción agrícola nacional. Es decir, los aldeamentos tendrían consecuencias positivas en la integración, pero también en el campo de la economía.

$Y$ era importante que los indios se encontraran atraídos por la idea de instalarse en aldeas. Para ello, aparte de la blandura, la sociedad blanca debía proporcionarles atractivos que Bonifacio plasmaba de forma un tanto ingenua. Y así:

cuando entren los indios en sus nuevas aldeas, deben ser recibidos con todo aparato y fiestas para que formen enseguida una idea grande de nuestro poder, riqueza y amistad. [...] Y como cumple excitarles la curiosidad y darles ideas muy altas de nuestro poder, sabiduría y riqueza, será conveniente que 
el misionero lleve una máquina eléctrica con los aparejos necesarios para en su presencia hacer las experiencias más curiosas y bellas de la electricidad e igualmente fósforos y gas inflamable para el mismo fin (ANDRADA E SILVA, 2005).

Poco parecía haber cambiado en el imaginario europeo desde los tiempos de las cuentas de vidrio del siglo XVI.

En dos puntos, el prócer se distanciaba del Directorio pombalino que había dominado la segunda mitad del siglo anterior: Bonifacio, frente a las prescripciones laicistas del Directorio pombalino, volvía a conceder protagonismo a los misioneros en el plan civilizatorio, colocándolos como el principal agente del plan dentro de la aldea, especialmente en relación con los indios "bravos, filhos das brenhas" 23 . El misionero sería el administrador de la cultura material del indio, de la catequesis, de la educación de adultos y la formación de los niños, así como el celador de su salud, intermediador en las relaciones entre indios y blancos y guardián de las familias indígenas. Y como eje del programa retornaba nuevamente a admitir como lengua vehicular la "lingua geral", e incluso en el plan que proponía para la formación de los misioneros indicaba el aprendizaje por éstos de las diversas lenguas indígenas.

\section{Otras propuestas a la Asamblea Constituyente}

Pero, más allá de las propuestas específicas relacionadas con ellos que hemos analizado, los indios aparecen también en el contexto de otras discusiones, con postulados y afirmaciones que nos revelan el pensamiento de diputados representativos respecto a las poblaciones aborígenes brasileñas, siempre motejadas de salvajes a quienes hay que sujetas y, en el mejor de los casos, de menores de edad necesitados de tutela. Incluso un diputado caracterizado como del ala más liberal, como lo era Borges Carneiro, consideraba a los indios no sometidos, a los en aquel momento célebres botocudos, como "monstruos egoístas y crueles" cuando comparaba con ellos a los mandos de un soldado a quien se había obligado a permanecer de guardia varios días.

El 1 de julio de 1822, cuando ya en Brasil se habían producido acontecimientos que resultaban alarmantes para los diputados europeos, como el "fico" del Príncipe Don Pedro o la desobediencia de decretos de cortes, se produce una encendida discusión en la que participan diputados de ambos lados del Atlántico y en la que se suscita la cuestión del nuevo patriotismo 
brasileño, diferenciado del portugués, hasta entonces dominante. Los diputados ultramarinos sostenían unánimemente - todavía - la unión con Portugal, pero manifestaban continuamente la diferencia frente a la metrópoli; frente a ellos, Fernandes Thomas, un diputado peninsular jacobino radical les objeta: "Brasil es nuestro (dicen ellos), ls leyes hechas para Portugal no han de tener allí entrada; somos brasileños, diferentes de los europeos", pero no hay más que una sola patria portuguesa igual a ambos lados del Atlántico. Los brasileños no son por tanto los únicos dueños de su territorio, como ellos se proclaman, ¿de dónde procede esa propiedad?, ¿Porque nacieron allí?. También nacieron allí los indios y no son los dueños del Brasil. Thomas distingue por tanto a los indios de los brasileños de origen portugués, que son los que están en la magna asamblea hablando de un nuevo patriotismo americano; son diferentes y, ni unos ni otros detentan la propiedad del Brasil (DIÁRIO DAS CORTES..., 1822g). Y dos días después, el 3 de julio, siempre en medio de la discusión sobre los deseos de independencia de Brasil, el diputado metropolitano Borges Carneiro rechaza que el reino ultramarino cuente con recursos para sostenerse ni para resistir a la amenaza de Portugal. Pero además, su planteamiento es altamente contradictorio y desagradecido para con su antigua metrópoli, pues "Yo no entiendo. Los brasileños, cuando ahora nosotros les anunciamos la causa de su regeneración, ¿caerán acaso en el estado de naturaleza del mismo modo que los indios entre ellos?" (DIÁRIO DAS CORTES..., 1822h).

Otras muchas opiniones en torno a los indios llegaron por unos $\mathrm{u}$ otros medios a la Asamblea constituyente, que van siendo conocidos a medida que son exhumados en diversos repositórios documentales. Marcelo Cheche Galves recoge en un artículo reciente la opinión de un abogado maranhaense, Manuel Santos Zacheo, acusado por sus enemigos de "demócrata sans culot" en las luchas independentistas y que escribia a la reunión lisboeta afirmando que era "necesario policiar a estos ciudadanos imposibles [...] porque solo el cautiverio puede policiar al indio y al negro y hacer así útiles a estos perezosos natos, ciudadanos imposibles, sin ambición cívica”. Frente a las opiniones integracionistas o paternalistas, la opinión dura y pesimista de este ciudadano liberal, convencido de que solo la mano dura y la semiesclavitud podían extraer utilidad a estos pobladores (ZACHEO, 2007).

Ninguna de todas estas propuestas llegó a nada. Todas ellas fueron enviadas a la Comissâo de Ultramar, en cuyo libro de registro Boehrer encontró la recepción de dos - las de José Caetano Ribeiro da Cunha y la de José Bonifacio -, mientras que las de Borges de Barros 
o Moniz Tavares ni siquiera están registradas ${ }^{24}$. La única excepción fue la propuesta de Zany y aun en su caso, las Cortes se limitaron a "oir" el parecer de la comisión - en la que figuraba el obispo y diputado de Pará, D. Romualdo da Sousa Coelho - que la había aprobado sin otra clase de actuación ulterior.

\section{Después de la Discusión: los indios en la Constitución de Portugal}

Es preciso recordar aquí cuál fue la presencia del indio en la Constitución de Cádiz, a efectos de poder establecer paralelismos del portugués y el posterior brasileño con otros textos constitucionales que abarcaban territorios en los que vivía población nativa en América; recordemos que el articulado de la constitución política de los Estados Unidos de América - 1787 - , otro territorio que cabría colocar en esas mismas circunstancias no alude para nada a la presencia de poblaciones aborígenes, como tampoco lo haría la posterior Carta de Derechos de $1791^{25}$, algo comprensible si pensamos en el pensamiento generalizado en aquel país, que consideraba a los indios como una especie de "naciones" ajenas, con las que se establecían pactos y se celebraban tratados ${ }^{26}$.

En España, el texto gaditano efectuaba la conocida declaración en el artículo I del Titulo I, Capitulo I que hacía referencia a "la Nación española": "La nación española es la reunión de todos los españoles de ambos hemisferios". Por tanto, eran españoles "todos los hombres libres nacidos y avecindados en los dominios de las Españas y los hijos de éstos" ${ }^{27}$. En el capítulo IV se definía quienes eran ciudadanos españoles, es decir, quienes poseían los derechos de ciudadanía: "aquellos españoles que por ambas líneas traen su origen de los dominios españoles de ambos hemisferios y están avecindados en cualquier pueblo de los mismos dominios" ${ }^{28}$. La excepción la recogía el artículo 22, que indicaba la vía para que los "originarios del África" fueran reconocidos como ciudadanos: la virtud y el merecimiento, los méritos. Por tanto, solo ellos quedaban en principio excluidos de la ciudadanía. Y también por tanto, los indios quedaban reconocidos como ciudadanos españoles de pleno derecho, en tanto en cuanto fueran indios "de pueblos y comunidades" y no se hallaran en la situación de "sirviente doméstico", lo que los excluiría según capítulo IV, artículo 25. Algo muy distinto fue el ejercicio real de los derechos de ciudadanía. Afirma Juan Marchena Fernández (2000) que las elecciones para diputados en España se realizaron por parroquias, mientras que en América cada diputado salió electo por los Ayuntamientos de las capitales, con lo que quedaban excluidos de la elección indios y castas al no 
pertenecer a aquellas instituciones ${ }^{29}$. El texto de Cádiz aun hacía otra referencia a la población india de aquella nación española. Era en el artículo 335 que confiaba a las futuras diputaciones provinciales la tutela de las "misiones para la conversión de los indios infieles" 30 .

La Constitución gaditana, que fue el referente más destacado para el constitucionalismo luso, tuvo su reflejo en la Constitución portuguesa de septiembre de 1822. Siguiendo las pautas de sus mentores hispanos, los legisladores portugueses declaraban en el artículo 20 del titulo II: "A naçao portuguesa e a uniao de todos os portugueses de ambos os hemisferios", mientras que la condición de ciudadano estaba indisolublemente unida a la de portugués como avecindado en el concejo dónde se hace la elección, excluyéndose, al igual que en la de Cádiz a los criados de servir, pero introduciendo una condición excluyente mucho mayor que en aquella: la de "los que no tuvieran empleo, oficio o modo de vida concreto", mientras que la ciudadanía pasiva era aun más restrictiva, quedando excluidos "los que no tienen para sustentarse renta suficiente, procedente de bienes de raíz, comercio o empleo" (CONSTITUCIÓN PORTUGUESA..., 2007), introduciendo también para el futuro inmediato la exclusión de los analfabetos. En principio, nada excluía a los indígenas del Brasil del ejercicio de la ciudadanía activa, e incluso a parte de ellos, de la pasiva. También al igual que el texto de referencia de los vecinos, el portugués introducía una alusión a los indios en aquella condición de seres destinados a ser civilizados que impregnó todas las apariciones de aquellos en las discusiones constitucionales: el último capítulo del texto, el cuarto, incluía en el postrer artículo, el 240, la obligación que se imponían las Cortes y el gobierno de fundar y conservar establecimientos destinados a la "civilización de los indios" (CONSTITUCIÓN PORTUGUESA..., 2007).

En la discusión de estos artículos en agosto de 1822 (DIÁRIO DAS CORTES..., 1822j) se suscitó un debate en el que se produjo una interesantísima aportación del diputado bahiano Cipriano José Barata ${ }^{31}$. Este sostenía que la redacción del artículo que determinaba la condición de ciudadano era buena para Portugal, pero debía ser precisada en aquello que se refería a Brasil. Defendía Barata que el vocablo "portugués" debía ser sustituido por "individuo", de manera que los derechos de ciudadanía fueran aplicados a cualquiera, fuera o no nacional. Pero fue su objeción al artículo en que se delimitaba qué era la nación portuguesa, la que le hizo desarrollar una interesantísima disertación, que no me resisto a reproducir en su totalidad. Tal como estaba redactado, decía el diputado, podía producir gran malestar en los pueblos de Brasil por excluyente. Su propuesta era mucho más 
abarcadora. El artículo, decía el diputado radical, debe ser modificado para recoger que:

La nación portuguesa es la reunión de todos los portugueses de todas las castas de ambos hemisferios. No piense el soberano Congreso que ello resulta indiferente: en Brasil tenemos portugueses blancos europeos, y portugueses blancos brasileños; tenemos mulatos, que son los hijos de todos aquellos portugueses con las mujeres negras, sean éstas criollas del país o sean de la costa da Mina, Angola, etc.; tenemos también mulatos, hijos de la combinación de los mismos mulatos y tenemos cabras, que son los hijos de los mulatos con las negras; tenemos caboclos o indios naturales del país; tenemos las mezclas de éstos, esto es, los mamelucos, que son el producto de los blancos mezclados con los referidos caboclos y tenemos los místicos, que son la prole de los indios combinados con la gente negra. Además de todo ello, tenemos también negros criollos, que son los nacidos en el país y finalmente tenemos los negros de la costa da Mina, Angola, etc.

La falta de cuidado em estos artículos puede producir um gran mal, porque toda la gente de color em Brasil clamaria porque le querían quitar los derechos de ciudadano; por esto digo que la palabra 'português' en Brasil es equívoca; concluyo pues que se debe excluir cualquier duda en el articulado, porque todos aquellos citados habitantes del reino de Brasil siguen la misma religión, hablan la misma lengua, obedecen al mismo rey, abrazan y defienden la misma Constitución libre. [...] Los mulatos, cabras, criollos, los indios, mamelucos y místicos, son gentes todas nuestras, son portugueses y ciudadanos muy honrados y valerosos, ellos en todo momento probarán cuanto peso tiene aquel país, haciendo la defensa de él y concurriendo a su engrandecimiento en la agricultura, en el comercio y en las artes. Hemos visto grandes héroes en todas aquellas razas. Es preciso recordar cuanto hicieron para librar a las províncias de los asaltos de muchos indignos señores del país nuestros adversários; hay que recordar a titulo de ejemplo todo lo que hicieron para expulsar a los holandeses. [tras citar ejemplos de heroísmo indígena en los tiempos de la invasión holandesa, Barata da cuenta de una de las escasas acciones indias en relación con el fin del antiguo régimen en Brasil] en nuestros dias vimos al caboclo Joaquim Eusébio de Santa Anna, capitao mor de la villa de Abrantes, ser de los primeros que actuaron en la revolución constitucional en Bahía el dia 10 de febrero del año pasado, ostentando el mayor valor y ofreciendo la vida por la salvación de la patria. [...] En todos los conflictos y victorias siempre se hallaron los briosos y valentísmos mulatos, cabras, mamelucos y místicos y concurrieron con los demás para la salvación del país, 
incluso cuando estaba desamparado de la nación portuguesa y del rey Juan IV que ordenaba entregar aquella provincia de Pernambuco a los holandeses enemigos. Pregunto yo: ¿fueron los portugueses y los blancos solo los que hicieron hazañas y salvaron a la patria?. No por cierto, fueron todos juntos. ¿No fueron ellos los que unidos libertasron a Bahia, Rio de Janeiro, Maranhão, etc.?. Fueron, sin duda alguna. Luego es evidente que se debe sustituir la palabra portugues por individuo en cosas de Brasil. Por eso el artículo debe quedar así: son ciudadanos portugueses todos los hijos de portugueses o de brasileños, aunque sean ilegítimos, de cualquier color o calidad, nacidos en el reino de Brasil y asimismo todos los criolos y los libertos.

Pregunto, ¿cual será más estimable ciudadano, el mulato o negro bien educado y bien conducido, sabiendo leer, escribir, sabiendo latín, francés, inglês, filosofia, etc. o un português blanco ignorante y de mal comportamiento?. Creo que será el mulato o el negro. ¿Quien merecerá más atención en la sociedad?. Un negro honrado que profesa un arte $\mathrm{u}$ oficio útil que posee propiedades urbanas o rústicas, o el europeo blanco, borracho y sinvergüenza, o algún miserable de ralea de color blanco?. Creo que nadie dejará de preferir al mulato o el negro, o cualquiera que sea la variación de color. Por consecuencia es necesario comprender a todos en Brasil como ciudadanos. Yo deseo que el soberano Congreso permanezca en la inteligência de que em el acta adicional se deben hacer muchas adiciones o disminuciones saludables em el reino de Brasil y por eso útiles a la nación. Lo contrario ha de descontentar y excitar a aquellos pueblos a la desobediência y a la revuelta, sin que después se puedan aplicar eficaces remédios (BARATA, 1822j).

Aun otras cuestiones interesantes se manifestaron en la discusión en torno a la ciudadanía, pero quizá una de las de más peso se suscitó en el debate en torno al último artículo constitucional, aquél en que se hacía referencia a la "civilización de los indios", el diputado Luiz Monteiro propuso que a la frase "civilización de los indios" se añadiese "y gradual extinción de la esclavitud". La Asamblea decidió no incluir tal principio en la Constitución y dejarlo para que apareciera en una posterior reglamentación. El interés de la propuesta es sobre todo el de la aparición de la idea abolicionista, aunque no pasara adelante, entre los parlamentarios, lo que supuso un primer toque de alarma entre los círculos esclavistas ultramarinos (DIÁRIO DAS CORTES..., 1822l).

Llama la atención la indiferencia de las Cortes frente a la cuestión india, pero aun más la escasa atención de los propios diputados de Brasil. Los papeles de las Cortes albergan cientos de planes, cartas y sugerencias llegadas de Brasil y relativas a otras materias. Solo las que hemos visto se 
preocupaban de los nativos, una parte importante de la población a la que representaban.

\section{LOS ÍNDIOS Y LA REVOLUCIÓN VINTISTA}

¿Cuál fue la reacción de los indígenas ante el fin del Antiguo Régimen y el advenimiento del nuevo en Brasil? Aparte el relato que hemos visto de Cipriano Barata, contamos con el testimonio del mismo Francisco Ricardo Zany al que más arriba veíamos presentando su propuesta a las Cortes lisboetas. En carta de éste al Emperador Pedro I, el ítalo-paraense daba cuenta de la situación de la zona de Río Negro en los primeros tiempos tras la llegada de las noticias de la revolución en la metrópoli. Describía aquel la situación antes de enero de 1821, cuando los indios "se conservaban aun subordinados", cuidando sus labores agrícolas los aldeados, pagando los diezmos, mientras las fábricas reales todas trabajaban y había indios suficientes para su manejo; con su producto se pagaba a todos los empleados de la administración y a las tropas de línea, al tiempo que los labradores y los comerciantes tenían indios para su trabajo. Pero

después que apareció una Constitución portuguesa y se retiró el gobierno designado por el Soberano y se eligió una Junta popular con ideas mal entendidas de libertad, ya no se llama a los indios para los trabajos públicos y los de Vuestra Majestad, porque eran ciudadanos y no se les podía obligar a trabajar y con esas doctrinas embutidas en la cabeza de los indios en su idioma, descendió el trabajo de las fábricas, de la agricultura y del comercio, porque el indio había perdido aquella sujeción y respeto al gobierno y ya no tenía aquel miedo de ser llamado a servicios y, como consecuencia, dejaba la mayor parte de ocuparse de la labranza y no querían servir a los particulares, volviendo a la selva, donde viven en la ociosidad que es su propia condición (REIS, 1977, p. 116-123).

No son muchos los testimonios en torno a la reacción indígena al nuevo sistema constitucional, de ahí el interés de éste ${ }^{32}$. Detrás de su ideología reaccionaria Zany, ¿ retrata la verdadera situación o la ideología y el temor a verse arruinado por falta de brazos - él era un propietario agrícola - le hacen tener una visión distorsionada de la realidad?. ¿Es trasladable ese informe a otras partes de Pará, - no olvidemos, el primer territorio en sumarse a la constitución -, del norte o del conjunto de Brasil?. Lo desconocemos BARATA, 1822j). 


\section{Los Indios y la Assembleia Constituinte do IMPERIO}

Tras los acontecimientos, suficientemente conocidos, que tuvieron lugar entre enero de 1821 y fines de 1822 , se consumó la separación de Brasil respecto a Portugal y comenzó en una Asamblea de representantes (RODRÍGUES, 1974) el proceso de elaboración de un texto constitucional en abril de 1823. El carácter multiétnico de la sociedad a la que tal texto iba destinado a regir pronto emergió en las discusiones. Y fue el artículo $5^{\circ} \mathrm{del}$ proyecto constitucional, que definía quienes son brasileños, uno de los que mayor discusión provocó de todo el texto (ANAES DO PARLAMENTO..., 2007). La propuesta constitucional definía como brasileños a los nacidos en Brasil, hombres libres y esclavos libertos. Y ahí surgió como tema de discusión la distinción entre "brasileños" y "ciudadanos brasileños". El diputado França argumentó que había que establecer distinción según la calidad de la problación y así, los negros son nacidos en Brasil pero no son ciudadanos brasileños. Por tanto, había que hacer la diferencia: brasileño es el que nace en Brasil y ciudadano brasileño aquel que tiene derechos cívicos y así, los indios que viven en los bosques son brasileños, pero no son ciudadanos hasta que no "abracen nuestra civilización". Conviene por tanto hacer diferencia por ser la población de Brasil una población muy heterogénea. Se trataba del reconocimiento del carácter multirracial de la población y de la búsqueda de la diversidad en el encaje constitucional.

Pero, ¿cuáles son las razones de la no inclusión de los indios entre los que gozan de derechos de ciudadanía?. El diputado Montezuma, uno de los más activos de la Asamblea lo planteaba:

los indios no son súbditos del Imperio, no lo reconocen, viven en guerra abierta con nosotros. No tienen derechos porque no reconocen deberes. No deben ser despreciados, antes deben facilitársele medios de llevarlos a la civilización y el hecho de nacer con nosotros, en el mismo territorio, nos impone tal deber (ANAES DO PARLAMENTO, 2007).

Por supuesto, mucho menos podían serlo los esclavos, que son solo cosas o propiedad de alguien.

No todo el mundo estaba de acuerdo con esa distinción entre "brasileño" y "ciudadano brasileño" e indicaba que debía hablarse solo de brasileños, pues la Constitución no es quien para dar o quitar el título a los nacidos en Brasil, como no dejará en ningún caso de ser paulista el nacido en Sao Paulo o minero el que lo ha hecho en Minas. Pero França contraargumenta: 
el proyecto indica que los hombres libres nacidos en Brasil son ciudadanos brasileños. Pero el tapuia, nacido en Brasil y libre no es ciudadano aunque sea brasileño. Solo será ciudadano cuando acepte nuestras costumbres y nuestra civilización. Argumentos semejantes empleaba el diputado Arouche Rendon, que tiempo atrás había presentado un proyecto para la civilización de los indios con grandes semejanzas con el presentado en Lisboa - y más tarde a la propia asamblea reunida en Río -: no es exacto que todo los hombres libres nacidos y habitantes en Brasil sean ciudadanos brasileños. No lo es el botocudo, que nace en Brasil, que allí habita y que es libre, como no lo es el esclavo que obtenga carta de libertad, pues un africano liberto, lo más que puede llegar a ser es un extranjero y no un ciudadano brasileño (ANAES DO PARLAMENTO..., 2007). El diputado Carvalho e Melo incluso, mientras declaraba que Brasil necesitaba más que nadie de pobladores, lamentaba que hubiera tenido "la desdicha de importar bárbaros de la costa de África y de la existência de bárbaros indígenas que expulsamos, exterminamos y casi extinguimos" (ANAES DO PARLAMENTO..., 2007).

La discusión continuó con sutiles distinciones entre la calidad o no de ciudadano o bien si todos son ciudadanos, pero no todos gozan de derechos políticos. Obviamente, ni un solo diputado defendió la universalidad del goce de tales derechos. Al final, la constitución no establecería tal distinción, si bien el carácter censitario del texto excluyó de un plumazo a una buena parte de la población; obviamente entre esa fracción, a los indios.

Paralelamente a las discusiones constitucionales, que constituían el núcleo del trabajo de la Asamblea, funcionaron comisiones que se encargaron de diversos problemas de caracter econômico y social; eran las de comercio, legislación, salud e instrucción pública. Intentaban poner en pie la administración de um país naciente. Una de éstas comisiones estaba destinada a buscar soluciones al problema, que entonces resultaba muy acuciante, de la falta de población y de la necesidad de colonizar el país: la comisión de colonización, que en realidad funcionó como una comisión de colonización, civilización y catequesis de los índios.

Nuevamente, José Bonifacio, dimitido en su cargo ministerial y convertido en diputado constituyente, presentaba a dicha comisión las propuestas que ya habían sido enviadas por él a las Cortes de Lisboa ${ }^{35}$. El 18 de junio, la comisión daba su parecer sobre los "Apontamentos"; reconocían los miembros la importancia de la materia que tocaban y los consideraban "un trabajo precioso, resultado de profunda filosofía y consumada pericia en la marcha gradual de la civilización del género humano" (ANAES DO PARLAMENTO..., 1823) ${ }^{36}$. Pero no pasaron de ahí, limitándose a recibir 
y agradecer su envío y a mostrar su agrado por ello. Por segunda vez, una asamblea parlamentaria dejaba pasar un documento tan trascendental y que trataba una materia tan central sin entrar siquiera a discutirlo.

Cuando la Asamblea había ya finalizado abruptamente sus sesiones, en diciembre de 1823, José Arouche de Toledo Rendon, que había sido director general de las aldeas indígenas de la provincia de Sao Paulo y conocía bien la realidad de sus poblaciones, presentó una memoria elaborada en 1798 y actualizada sobre la situación de tales aldeas y propuso medidas para el trato con los indios (MOTA, 2008). Criticaba de entrada las políticas indígenas anteriores, tanto las aislacionistas de los padres que impedían a los indios civilizarse para mantenerlos como esclavos en sus haciendas, como las de las administraciones laicas y sus administradores generales y cámaras municipales, que solo se habían obsesionado con la explotación de los indígenas. La primera medida debía de ser la de "aldear" a los indios salvajes y errantes de las selvas, pero solo a estos. El entendía que era provechoso que los indios fueran aldeados por etnias, siempre cerca de las poblaciones de los blancos, que tuviesen un religioso para proporcionarles el bien espiritual y un administrador para el temporal que los acostumbrara al trabajo de forma que de él obtuviesen su sustento. Debería igualmente acabarse con la bárbara costumbre de atacar a los indios como enemigos, excepto en caso de defensa; ellos nos temen y desean nuestra amistad. Conviene separar de ellos a sus hijos, o a parte de ellos, cuando se encuentre conveniente, entregándolos a buenas familias que los sepan educar y que en premio se beneficien de sus servicios $^{37}$. Cuando más tarde Rendon -1842 - reedite sus propuestas indicará que la atracción a los indios podría convertirlos en la mano de obra que la agricultura necesitaba, aliviando así los inconvenientes de la importación de esclavos de África.

Una vez reunida la nueva Asamblea postgolpe de estado imperial y a una nueva comisión de colonización uno de los representantes, D. Romualdo Antonio de Seixas, presentaba un proyecto para dividir Grao Pará en dos provincias y en ese contexto se refería a la situación de los indígenas. Si tantos memoriales veían en la dispersión de la población india la razón de la escasez de mano de obra, D. Romualdo la atribuía al mal trato inferido a los indígenas por las autoridades, ahora del Imperio ${ }^{38}$. Era imprescindible cambiar la forma de relacionamiento con los indígenas, civilizarlos, cristianizarlos para transformarlos en una población útil al progreso de la provincia. Siempre planeando la idea de la "utilidad" de los indios, ahora que las trabas británicas al tráfico africano dificultaban y encarecían la reposición de la mano de obra negra. Frente a la propuesta de Seixas, otros diputados como Clemente 
Aguiar opinaban que era imposible civilizar a los indios y solo la fuerza era la única fórmula de relación con ellos (ANAES DO PARLAMENTO..., 1826). Entre los miembros de la comisión dominaba la sempiterna cuestión de la diferencia entre los indios "civilizables", susceptibles de ser tratados con blandura y los "gentíos bravos" recalcitrantes, a los que se aplicaría a fuerza de las armas. La comisión recibió encuestas sobre la situación de los indios de parte de los Presidentes provinciales, pero nada se llevó a cabo.

\section{Los Indios en los Sucesivos Textos Constitucionales de Brasil}

Los trabajos y debates de la Asamblea Constituyente culminaban en comisión el 1 de septiembre de 1823 con la redacción de un texto constitucional de 272 artículos en el que los artículos referentes a la ciudadanía obviaban la separación brasileño-ciudadano que había ocupado varios días la discusión previa a la redacción del artículo correspondiente. En el título II, capítulo I, artículo 5 del texto indicaba que eran brasileños "todos los hombres libres nacidos habitantes de Brasil y en él nacidos". A ellos se unían los esclavos que obtuviesen carta de libertad. La letra de la ley otorgaba por tanto la condición de ciudadanos a los indios. Pero el ejercicio de los derechos políticos quedaba restringido a aquellos ciudadanos que dispusieran de una renta mínima, lo que expulsaba del ejercicio político a la mayoría de la población libre (ANAES DO PARLAMENTO..., 1826). Solo al final del texto, en el último capítulo, aparecían los indios, al igual que en su modelo, la constitución vintista de Portugal, citados como objeto de catequesis civilizatoria. El artículo rezaba así: [la autoridad] "tendrá igualmente cuidado de crear establecimientos para la catequesis y civilización de los indios, emancipación lenta de los negros y su educación religiosa e industrial" (ANAES DO PARLAMENTO..., 1826).

El 11 de noviembre de 1823, a punto de culminar los debates en la promulgación del texto constitucional, se producía el golpe de Estado por el que el gobierno imperial procedía al cierre de la Asamblea. Los acontecimientos, suficientemente conocidos, culminaron con la promulgación de una Carta otorgada imperial ${ }^{39}$, texto constitucional datado el 25 de marzo de 1824. La carta, que constituiría, con enmiendas y modificaciones, la ley fundamental del Imperio hasta su caída, representaba sobre todo una mayor presencia de la figura del Emperador, tanto a través de más amplias competencias en los tres poderes tradicionales, como de la inclusión de un cuarto poder, el "poder moderador", en el que el monarca era determinante. 
En la constitución del 24, el Imperio del Brasil era la asociación política de todos los ciudadanos brasileños y éstos son todos los allí nacidos, sean ingenuos o libertos, excluyéndose del ejercicio de los derechos políticos a aquellos que no gozaran de la renta de 100 mil reis y los libertos en el segundo escalón de la elección indirecta. Pero, a diferencia del proyecto constitucional de la Constituyente o de su antecedente portugués, no aparece una sola alusión a las poblaciones indígenas.

\section{Los Indios, Parte Activa del Proceso de Independencia}

Antes de pasar adelante, debo aclarar que entiendo, siguiendo en ello a muchos historiadores brasileños actuales, que la independencia de Brasil no se reduce al estricto proceso de ruptura que tiene lugar en 1822. Como tal considero todo el amplio lapso temporal que se prolongó a lo largo del primer imperio y del tiempo regencial y sus luchas hasta la definitiva consolidación de la monarquía constitucional con la mayoría del segundo Emperador, un tiempo en que la forma de estado y la configuración territorial definitiva están aun por definir. La independencia, considerada en el largo tiempo que llega hasta el fin de la Regencia, fue un proceso largo y penoso, acompañado de manifestaciones de violencia en todas partes, pero sobre todo en la periferia norte ${ }^{41}$. En este contexto, el grito de Ipiranga no fue más que la forma que encontraron las elites para frenar las ideas subversivas, mantener la dinastía y con ella todos los privilegios del sistema colonial y gaantizar sus intereses económicos y la permanencia de la esclavitud. Y en un Estado Nacional que se iba configurando como excluyente del derecho a la ciudadanía y del acceso a la tierra para la inmensa mayoría de la población, es explicable que ésta manifestara su descontento de forma constante. El estado postindependencia ahogó las aspiraciones y las esperanzas que pudo despertar en una gran mayoría de la población: blancos y mestizos libres y sin propiedad, y por supuesto, negros libres, esclavos e indios; todos ellos fueron marginados de cualquier posibilidad de participación política. Además, la independencia arrastró una extrema centralización del poder en la capital imperial contra las expectativas creadas en las provincias, cuya adhesión al fin del gobierno colonial fue unida en amplias capas de la población a la esperanza de autonomía regional, alentada en el tiempo de las Juntas derivadas de la constitución lusa de 1820. El triunfo del modelo centralizado solo llegó tras casi tres décadas de luchas y levantamientos con amplia participación de todas las capas de la población.

$Y$ en esas luchas, aun cuando pueden encontrarse indígenas participando en acciones de carácter armado en el tiempo de la independencia a 
lo largo de todo el territorio de Brasil, conocemos mejor, por haber recibido mayor atención de los historiadores - ello a causa del mayor peso demográfico de aquellos y de la mayor profusión de levantamientos - el caso del norte y el nordeste en el tiempo denominado "ciclo de las insurrecciones liberales", que abarca allí el amplio período que se extiende de 1817 a 1848 en el que los movimientos contaron con abundante presencia indígena, tanto en las tropas rebeldes como en las de la represión. En todas sus acciones, al involucrarse en aquellas "brigas de branco" (CARVALHO, 2002), ${ }^{38}$ los indios buscaban siempre la defensa de los intereses superiores de la comunidad, mientras que los europeos, al envolver a indígenas en sus desavenencias no hacían más que continuar una larga tradición colonial de buscar apoyo en las naciones indias en sus luchas.

$\mathrm{Y}$ en la primera mitad del siglo XIX, la tradición continuó. La "gente da terra" siguió siendo una aliada importante en la escisión que se produjo en el momento de la independencia (CARVALHO, 2002). Las elites blancas se escindieron en conservadores - partidarios del centralismo monárquico y del mantenimiento intocado de las estructuras coloniales - y liberales - federalistas, partidarios de una mayor autonomía provincial y de una profundización en la apertura económica -; pero las disputas tenían generalmente poco de ideológico y mucho de lucha por la tierra o por el control sobre las poblaciones locales o provinciales. Y en ellas - las insurrecciones pernambucanas de 1817, la igualmente nordestina Confederación del Ecuador de 1824 y la llamada "Guerra dos Cabanos", la Cabanagem paraense de 1835-40 o la balaiada maranhaense de 1838-41 -, las elites arrastraban a la participación a las capas más bajas de la población que encontraban así ocasión de expresar sus propias reclamaciones. Y era lógico que las comunidades indígenas participasen también para intentar conseguir alguna de sus reivindicaciones. A cambio, para los señores, la participación de los indígenas tenía la utilidad de la aportación de grupos considerados capaces de convertirse en soldados bravos y aguerridos.

La movilización de colectivos indígenas aldeados resultaba sumamente facilitada por la estructura militar que proporcionaba a las aldeias la legislación colonial vigente, que preveía el encuadramiento de los indios bajo el mando de los "capitâes-mores y de un conjunto de oficiales subalternos, una jerarquía de carácter colonial que se había superpuesto y en parte sustituido a las jerarquías tradicionales indígenas" ${ }^{40}$.

Y de hecho, la movilización es constatable, según pudo comprobar Marcus de Carvalho (1998), en todas las luchas ocurridas en Pernambuco 
en la primera mitad del siglo XIX. En la primera de ellas, la denominada "Revoluçao Pernambucana" de 1817, la Corona reclutó a indígenas que, al entrar en la capital, Recife, provocaron desórdenes que causaron la alarma de los habitantes blancos ${ }^{41}$. Y la colaboración de los indígenas en la reacción realista puede constatarse en otros ámbitos: indios aldeados cerca de los límites de Pernambuco con Paraíba fueron agentes muy activos de la represión a los revoltosos al mando de su director, mientras que en la propia provincia de Paraíba, escenario también del levantamiento pernambucano, hubo presencia indígena entre las tropas de la reacción.

Siempre según M. de Carvalho, los indios de Brejo da Madre de Deus, sistemáticamente acusados por las fuentes como absolutistas contrarios a la causa de Brasil en tiempos de la Confederación del Ecuador - 1824 - sufrieron un ataque por parte de las tropas del gobierno liberal de la confederación en el que muchos fueron muertos. Otros, enviados a Recife, fueron sometidos a esclavitud, acusados de pertenecer en cuerpo y alma al partido portugués.

En 1823, muy poco antes del estallido de la confederación del Ecuador, los indios de Cimbres "alimentados desde la cuna - se informaba - con la doctrina del realismo y ahogada su razón por una inmensa ignorancia, son por naturaleza fanáticos, realistas absolutos". Se acusaba a los indígenas de haberse ya levantado anteriormente, en 1822, contra la independencia del país, "oponiéndose a la elección de diputados" y "afirmando obedecer solo a don Joao VI, de quien son adeptos en exclusiva”...."solo dan vivas a don Joao VI y son contrarios a la causa del Brasil".

¿Cuál era la razón de la opción prometropolitana de las comunidades indígenas?. Hay aquí algunos signos que pueden llegar a establecer paralelismos con el caso de tantas comunidades indígenas en los países e obediencia hispana. Es evidente que la veneración por el monarca era un instrumento central en las enseñanzas de las órdenes religiosas, a las que las comunidades nativas estaban tan ligadas. El Patronato Real, en el Brasil portugués como en las Indias castellanas, era un instrumento de estrecha unión del monarca con la Iglesia y las órdenes religiosas. Y al llegar la independencia, muchas de esas órdenes mostraron escaso entusiasmo por el nuevo orden ${ }^{42}$

Pero el adoctrinamiento de los indígenas por parte de los frailes no es razón suficiente para explicar la elección de los indígenas en ese periodo. Hay otra razón que aclara la opción mayoritariamente realista de los indígenas en las luchas independentistas. El rey era la última instancia a la que recurrían los campesinos contra las invasiones de tierra que practicaban los señores blancos vecinos. Al igual que en tantos territorios de la América española, en la opción entre los criollos blancos y la monarquía, los indígenas veían 
en ésta una salvaguardia de sus derechos. Más aun, cuando los vacíos de poder visibilizados en la deposición de los antiguos gobernadores portugueses permitieron en muchos casos el avance de los fazendeiros sobre las propiedades indígenas.

Dantas y Carvalho buscan la razón para explicar el que la opción por el Rey primero o por el depuesto Pedro I después fuera más seguida que la opuesta por los indios. Según ellos, la transferencia de la Corte a Brasil y la posterior aclamación como Emperador de su hijo, había servido para avivar entre los nativos la mitificación de la figura real, largamente trabajada por los misioneros en el imaginario de esas poblaciones como un señor todopoderoso cuasidivino, representante de Dios en la tierra y a quien debían obediencia. En nombre del rey se les llevó a las aldeas, en nombre del rey se les dieron derechos sobre pedazos de tierra cuyos títulos iban firmados por él. A él recurrían cuando sus tierras eran atacadas y a veces recibían amparo y en el siglo XIX crecía el número de peticiones a Joao VI primero y a D. Pedro después suplicando su "paternal protección". A través de la documentación se trasluce la idea casi mesiánica de padre que en los indios había calado respecto al monarca. Un padre de quien esperaban protección y a quien debían en contrapartida obediencia y fidelidad. Todo ello ayuda a entender la razón de la amplia preferencia de los indios aldeados por el bando restauracionista en norte y nordeste. La abdicación y la salida de D. Pedro para Portugal fue sentida por muchos de ellos como una orfandad, cuando además coincidía con la gran ofensiva de los señores sobre sus tierras. El discurso restaurador caló en poblaciones que veían en la realeza la garantía de sus derechos sobre las tierras, algo que también sucedió en muchos de los nuevos países hispánicos.

Pero no solo entre las filas realistas había nativos. Hubo algún caso - menos común que los anteriores - en el que algún dirigente indígena sufrió prisión por su afiliación en las filas de los republicanos. En realidad, la presencia india tenía que ver, mucho más que con razones ideológicas, con la opción del señor o miembro de la élite del que dependían en la relación clientelar y semivasallática característica del tiempo o también con lo que la comunidad juzgaba que era su interés. De todas maneras, en estas "brigas de branco" era mucho más común encontrarlos en el campo del poder que en el de la rebeldía. Carvalho (2002) cita también la presencia de elementos indígenas en el tiempo de la Confederación del Equador - 1824 -, cuando miembros de comunidades residentes en valles del rio Jacuipe, en Alagoas, fueron movilizados por las tropas centralistas para contribuir al aplastamiento de los rebeldes; aquellos indios vivían en tierras propiedad de la Corona y 
según el autor al que seguimos, su acción les sirvió para reafirmar la garantía de su disfrute de las tierras en que residían.

Pero, cuando se produce la Cabanada, una larga rebelión contra el gobierno de la regencia con foco en Pará, los indios de Jacuipe, que reaccionaron contra una tentativa de reclutamiento militar, se mostraron como "feroces rebeldes"; para combatirlos, el gobierno provincial reclutó a los también indígenas del término de Barreiros, que seguían aquí a los dueños de la tierra, beneficiarios de la nueva orientación del gobierno surgido de la caída de Pedro I (CARVALHO, 1998). En 1846, tras una fricción de la aldea india con la citada villa de Barreiros, cuando la cámara municipal exigía el castigo de los vecinos de aquella, el Jefe de Policía se negó alegando que aquellos nativos habían sido muy importantes en la represión de la Cabanada. Más tarde, cuando cae la facción praiera de los liberales gobernantes en el gobierno pernambucano - 1848 - sus componentes se rebelan y levantan la praieira. Los indios de Barreiros se levantaron con sus aliados los señores liberales. M. de Carvalho indica que muchos debieron ser los indios que murieron combatiendo con y por los praieiros.

En ocasiones, la acusación de prolusitanos a los indios era interesada y falaz. Nativos que adhirieron a la confederación del Ecuador y fueron derrotados huyeron a la vecina Alagoas. Cuando regresaron en 1830, las autoridades entonces gobernantes afirmaron que su vuelta obedecía a su deseo de levantar la bandera portuguesa y aprovecharse para saquear y robar.

El repetidamente citado Marcus de Carvalho estudia más ejemplos de participación indígena en las luchas nordestinas en torno al tiempo de la independencia. A veces se produjeron cambios de lealtades que tienen una clara explicación: la defensa sobre todo de sus intereses. En general, los indios trataban de evitar verse involucrados en las luchas de los blancos. Pero no siempre lo conseguían y a veces se veían obligados a seguirlos, estuvieran aquellos en el lado del poder o en el de la rebelión, se tratara de liberales o de conservadores. Seguían así, como decíamos, las tradicionales redes clientelares. Pero a veces, la ruptura del consenso de las elites permitía un margen de opción a los indios que éstos aprovechaban desvinculándose de lo que sería su opción clientelar y optando por una negociación con el mejor postor en defensa de sus intereses.

Tal como observó Manuela Carneiro da Cunha, la máxima especialista en la historia de las comunidades indígenas en el siglo XIX, hasta la promulgación de la legislación de tierras de 1850, la legislación reconocía explícitamente la posesión de tierras que habían ido siendo concedidas a las aldeas indígenas, pero aun así, esa posesión debía ser siempre defendida frente a la 
depredación de los señores, directos adversarios de aquellos. Pero cuando los señores dividían sus opiniones en facciones, necesitaban de los indios y sus armas para inclinar la balanza a su favor, lo que redundaba en beneficio de éstos. En esa ocasión, los indios sabían escoger el lado que estaba más cerca de sus intereses. Y ello significó en ocasiones que los indios cambiaron de bando y pudieron encontrarse en un momento en el bando conservador o en el portugués y en el siguiente en el independentista o el liberal. Con ello no hacían sino seguir la estela de sus propios intereses; su participación no era más que una faceta más de su secular resistencia al dominio colonial ${ }^{43}$. Los indios escogían sus aliados entre conservadores, absolutistas o liberales conforme a sus conveniencias y también según la capacidad de cada aldea de elegir. Si era preciso y posible, incluso cambiaban de lado. Había por tanto desde la perspectiva indígena un límite para envolverse en las "brigas de branco" y ese límite lo marcaban los intereses de la comunidad.

El supuesto absolutismo indígena no era, a decir de Carvalho, más que una opción para la oposición que hacían a los señores de la tierra aliados de las facciones constitucionalistas urbanas que aprovecharon el momento del hundimiento del aparato burocrático del poder absoluto para avanzar sobre las tierras de las aldeas, lo que hacía que los indios, según una encuesta de 1824 no quisiesen "saber nada de Constituiçao"; el igualmente supuesto liberalismo de los indios de Jacuipe y Barreiros durante la Praieira obedecía a motivos semejantes pero opuestos

Se conoce hoy que las comunidades usaban de una facilidad organizativa para su movilización armada, la que le proporcionaba la pervivencia de antiguas jerarquías comunitarias de carácter paramilitar que databan del tiempo colonial, reforzadas por la legislación pombalina y que tenían en la cumbre al capitâo mor de aldeia y descendía en la comunidad a través de alféreces, capitaês, sargentos mayores, etc. que constituían el cuerpo de oficiales, unas jerarquías que fueron tenidas como puramente ceremoniales y que, sin embargo, hoy se sabe que poseían contenido ${ }^{44}$. El capitao mor era el interlocutor a quien se dirigían los que pretendían usar la fuerza indígena a su favor.

Como no podía ser menos, la participación indígena fue notable sobre todo en la provincia con mayor presencia porcentual de población nativa: Pará. Las especificidades de la historia anterior de esta provincia del extremo norte, su especial relación con Lisboa, su alejamiento respecto de la sede de la monarquía y el mayor peso de la población portuguesa en ella, hicieron de la adhesión a la independencia un acto tardío - tuvo lugar un año más tarde que en Río; la provincia y en su representación sus Juntas Gubernativas 
se mantuvieron hasta agosto de 1823 adheridas a las Cortes lisboetas - y revestido de una fuerte polarización. La temprana adhesión al movimiento constitucional de 1820 despertó grandes expectativas en la población paraense: los indígenas confiaban en la abolición de los trabajos obligatorios en las rozas y en las manufacturas de los señores próximos a las aldeas, de la misma forma que los negros esperaban la abolición de la esclavitud o la población blanca desfavorecida e incluso profesionales liberales atendían una mejora de las deplorables condiciones en que se hallaba la provincia y una disminución del control político y económico de los portugueses y sus aliados ingleses. El triunfo del imperio conservador fue sentido por una parte de la población como una intolerable imposición, lo que unido a una situación de profundas dificultades por la carestía y por lo que se sentía como un exceso de poder en manos de la elite de comerciantes portugueses, generó una profunda frustración. Todo ello conllevó una situación de inestabilidad y de motines y levantamientos constantes en el periodo de 1823 a 1835, unos movimientos populares con participación de negros, mulatos e indígenas que desembocó en 1833 en un estado de insurrección generalizada en la provincia, denominada la "cabanagem" 45 .

El desarrollo del movimiento es suficientemente conocido, pero tiene sobre todo importancia aquí señalar que, a decir de Caio Prado Junior (PRADO JUNIOR, 1979), fue, de todas las insurrecciones producidas en torno a la independencia de Brasil, la que revistió un aspecto más popular y menos monopolizado por la elite, el único en que las capas populares llegaron a ocupar la dirección. $\mathrm{Y}$, como es lógico en un territorio con tan fuerte peso de población nativa, los indios tuvieron un protagonismo muy destacado en la rebelión ${ }^{46}$. Esta, que se extendió por todos los ríos amazónicos, implicó a buena parte de las etnias paraenses y principalmente a mura y mawéc ${ }^{47}$; uno de los caciques mawé, Leao Crispim, fue uno de los grandes líderes cabanos.

El peso de los indios en el movimiento de Pará aumentó aun más cuando, tras la escisión en el liderazgo, Antonio Vinagre y Angelim se refugiaron en el interior. La consiguiente reorganización de sus fuerzas se realizó casi de forma total con tapuias, indios aldeados, cabocolos y negros, que se dirigieron a conquistar Belem, lo que consiguieron tras nueve días de lucha. La posterior derrota conllevó una terrible represión en la que murió cerca del 40 por ciento de la población, pero fue especialmente dura con los indígenas: en Tapajós se calcula que desapareció como consecuencia de la derrota cerca del 90 por ciento de los indígenas, mientras que se dijo que los mura pasaron de ser cincuenta mil en 1826 a quedar reducidos a seis mil tras el fin del levantamiento. Aunque las cifras deben tomarse con extrema 
cautela por cuanto no suficientemente contrastadas, sí que revelan la enorme incidencia de la represión entre los nativos ${ }^{48}$.

De la importancia de la participación indígena en el levantamiento da buena cuenta la relación de presos llevados al navío prisión "Defensora" en 1837: de 299 presos, 91 eran tapuias, 13 indios aldeados, mestizos con sangre indígena - cafusos y mamelucos - 63. Esos datos indican que el $73 \%$ de los implicados en la revolución eran indios o descendientes de tales. En cualquier caso, si los indios son citados constantemente como actores sociales de la cabanagem, hoy conocemos muy poco todavía respecto a su actuación concreta.

No todos los indígenas lucharon en el levantamiento en el lado de los insurrectos. Los mundurukus se convirtieron en aliados del poder contra los rebeldes. En ello influía, por un lado su ancestral enemistad con los mura, cabanos, y del otro la promesa de respeto a sus tierras. Visitados en 1852 por W. Rendón y L. Gibbon, expresaban aun su profundo desencanto por haber abandonado sus quehaceres para luchar con los blancos y haber recibido de éstos solo la ingratitud y el despojo de sus tierras (BARROS LARAIA, 1993).

También es conocida la presencia india en la insurrección conocida como "la Balaiada" (CORREIA DE ANDRADE, 1965), que se extendió por Maranhao, Ceará y Piaui desde fines de 1838 hasta fines de 1841 y que, aun cuando comenzó como un enfrentamiento intraelites, acabó oponiendo a las autoridades regenciales, los dueños de tierras y esclavos y los comerciantes de un lado y del otro pequeños propietarios, vaqueros, pequeños "fazendeiros", libertos e importantes contingentes de esclavos, etc. La participación como rebeldes en el territorio de Piauí de indios, que arrastraban una larga historia de guerra y opresión, de aldeamentos compulsivos y de expulsión de sus tierras para abrir camino a las grandes fazendas, es hoy bien conocida (MIRANDA DIAS, 1995). En el transcurso de la rebelión, sesenta parejas indias de Vila Vinosa, en Ceará, desertaron de su aldeia para unirse al levantamiento. Comentando el hecho, el presidente de la provincia afirmaba que el alistamiento voluntario de numerosos indios en ese y otros movimientos armados contra el gobierno eran el resultado de presiones sobre sus tierras y que ello valía igual para Ceará que para Maranhao y Pará (DANTAS; CARVALHO, 1992). Años antes los indios krahô, ubicados entonces en el territorio de Maranhao, resultaron valiosos aliados de las elites independentistas en la lucha por expulsar a las tropas portuguesas allí instaladas (BARROS LARAIA, 1993). 
EPílogo: y TOdo Siguió IgUAL

Al final, desde la dureza o desde la blandura, todas las propuestas, como luego sucederá con las presentadas a la Constituyente del Imperio, con la política seguida por el propio Imperio o por su sucesora, la República, eran políticas "integracionistas", propugnaban actuaciones cara a la "integración en la nación brasileña”, integración que pasaba por la incorporación de sus territorios y la apropiación de sus tierras (MOTTA, 2008). Una política que no fue exclusiva del Estado imperial brasileño; puede encontrarse en los otros Estados latinoamericanos que se encontraban en el proceso de construcción nacional con poblaciones indígenas de cierta entidad. Ninguno de ellos, Brasil incluido, aceptaba el carácter pluriétnico de sus sociedades. En palabras de M. Carneiro da Cunha, no se admite en toda esa primera parte del siglo XIX que los indios puedan constituir siquiera sociedades dignas de ese nombre ${ }^{49}$.

Si los indios pasaron por las discusiones constitucionales, a uno y otro lado del Atlántico, sin que se produjera modificación alguna respecto a su situación. Si su actuación en unos bandos u otros en las luchas que jalonaron la independencia pudo en casos muy puntuales producir alguna ventaja a grupos muy concretos, que se aliaron al bando vencedor, como grupo, a la altura de 1830 su situación se mantenía exactamente igual que en el momento de la llegada de la corte, más de veinte años antes. Solo en noviembre de 1830, el Senado del Imperio comenzaba a discutir una proposición para que se revocara la carta regia de noviembre de 1808 que permitía de forma legal hacer la guerra a los indios "salvajes" (SPOSITO, 2008). Solo ahí comenzaba tímidamente a discutirse la elaboración de una política indigenista del Estado Imperial. Pero la legislación indigenista del periodo 1822-1845 fue pobre y estuvo pulverizada en varias "instancias legisladoras", no existiendo una común para todo el imperio; además, el incumplimiento fue generalizado, sobre todo en el norte, dónde las necesidades de mano de obra hacían cerrar los ojos a la autoridad ante cualquier abuso ${ }^{50}$ Con la Regencia, el indio adquirió un estatus idéntico al de huérfanos, menores e impedidos ${ }^{51}$. Según uno de los más importantes estudiosos de los indios bajo el Imperio, Moreira Neto, los indios fueron los grandes vencidos y derrotados de la historia del Brasil y la pérdida del lugar que les pertenecía se consolidó precisamente con el Imperio. El modelo del Brasil imperial - como el de toda la élite latinoamericana - era Europa y era preciso autoidentificar al país como nación europea eliminando a indios y negros y sustituyéndolos por los deseados colonos blancos (MOREIRA NETO, 2005). 
La miserable realidad de los indios provocó el surgimiento de innúmeros movimientos de rebeldía, por ejemplo en el nordeste, después del fin de las rebeliones de la independencia y la postindependencia y sin vinculación con movimientos revolucionarios más generalizados. Aun cuando más localizados, trascendían el límite de la aldea; atacados en sus poblaciones, asustados por el creciente reclutamiento para las tropas imperiales, los indios huían hacia la selva, dónde continuaban su rebeldía aliados con otros grupos desposeídos de tierras, como esclavos huidos o pardos. El temor en el nordeste al surgimiento de una nueva "guerra dos cabanos" permeó todo el resto del siglo a la población blanca pernambucana (DANTAS; CARVALHO, 1992).

Los indígenas no fueron sujetos pasivos frente a la política asimilacionista del nuevo estado brasileño. Se opusieron al expolio de sus territorios y a su disolución en la población "nacional" de Brasil. Se manifestaron a través de la violencia armada o de actuaciones legales ${ }^{52}$ exigiendo la demarcación y la protección de sus tierras, utilizando así la propia legalidad que el Estado incumplía. Escribe Mota (2008):

las comunidades indígenas no fueron meros espectadores de las políticas trazadas por el IHGB e implementadas por las elites locales, fueron sujetos de su propia historia, analizando, elaborando y ejecutando políticas que les propiciasen el mantenimiento de sus territorios y de sus modos de vida (MOTA, 2008).

Y en cuanto a la actuación de los indígenas al lado de unos u otros actores de las luchas independentistas y postindependentistas, no hubo estrategia capaz de frenar el avance del latifundio exportador sobre las tierras indígenas. Los descendientes de los indios implicados en aquellas acabaron perdiendo las tierras comunales y convirtiéndose en cortadores de caña en los ingenios de los latifundistas ${ }^{53}$. Las poblaciones nativas del imperio de Brasil fueron objetivo, durante todo el tiempo imperial que siguió a la ruptura con Portugal, de una política general de exterminio indiscriminado, continuación lineal, a pesar de todas las discusiones y proyectos, de la promovida por la monarquía portuguesa en sus tiempos en el reino ultramarino ${ }^{54}$, bien es verdad que nunca llegó a concretarse en una política tan determinada como lo fue en la misma centuria la practicada en Estados Unidos o en Argentina.

Como señalábamos más arriba, paralela a la expoliación y exterminio de las comunidades indígenas, avanzaba, con el romanticismo, la idealización 
del indio como la encarnación del ser nacional en el movimiento indianista que inventaba un complejo mitológico, en la estela de Chateaubriand o Fenimore Cooper, en el que el tiempo de los indios representaba para Brasil la áurea Edad Media de los románticos. El indio se convierte en el símbolo de la nacionalidad, abriéndose así una línea divisoria entre el idealizado indio ficcional de la imaginación romántica y las comunidades contra las que el Estado brasileño se declaraba, de hecho, en guerra de exterminio (TREECE, 2008).

Significativamente, y al igual que sucedía en el tiempo de la corte en Brasil, mientras que los brasileños blancos avanzaban sobre las tierras de las aldeias y se acentuaba la presión, tantas veces sangrienta sobre los nativos, éstos seguían siendo, idealizados, el componente central de la imagen de Brasil, algo que se acentúa con la difusión del romanticismo europeo, que estimula en ultramar el denominado "indianismo". Se consideraba que los indios contemporáneos habían sufrido una profunda degeneración desde una especie de anterior edad dorada. Mientras tanto ideólogos, literatos y políticos seguían proponiendo la mezcla poblacional de europeos e indígenas como el futuro para el Brasil, para "formar uma naçao maravilhosamente organisada" (VON MARTIUS, 1845) ${ }^{55}$; asi, la raza degenerada e inferior contribuiría a la construcción de una nación nueva a medida que fuese asimilada y absorbida por la raza blanca. Para José de Alencar, uno de los más destacados literatos brasileños del siglo XIX, la consolidación de una cultura brasileña propia tras la independencia podría realizarse solamente si la mentalidad medieval aislacionista del colonialista luso se superaba con la unión "moderna" del indio y del europeo (ALENCAR, 1965). Pero el avance del contacto indios-blancos, preconizado por el indianismo desde Bonifacio, el mestizaje, lleva a la consideración de los indios de los aldeamentos con la negativa y descalificadora denominación de misturados. Frente a ellos se alzaban los indios "puros" del pasado, idealizados y presentados como antepasados míticos (DANTAS; CARVALHO, 1992). No era nada inocente; la presentación de los indios como población "misturada e mestiça" culminaría en la negación de la existencia de indios, con lo que decaían sus derechos históricos, por ejemplo a la posesión de sus tierras. Sería ya en la segunda mitad del siglo, doblado el cabo de los 50, cuando comience a detectarse en el discurso de la elite la aparición en el horizonte de la "teoría del blanqueamiento" dominante en la segunda mitad del siglo y se abandone desde la óptica del racismo cualquier idea de integración indígena.

Habría que esperar hasta casi doscientos años después de la independencia para que los indios vieran reconocido un espacio en el nivel 
constitucional. La Constitución de 1988 (CARNEIRO DA CUNHA, 1992b) abandona por fin la retórica y las metas asimilacionistas, estipula sus derechos y reconoce "a los indios su organización social, costumbres, lenguas, creencias y tradiciones y los derechos originarios sobre las tierras que tradicionalmente ocupan, correspondiendo a la Unión demarcarlas, proteger y hacer respetar todos sus bienes". Aunque su cumplimiento deja mucho que desear, como es suficientemente conocido, al menos hay un texto legal en que apoyar su defensa.

\section{INVISIBLE AND FORGOTTEN: INDIANS AND BRAZILIAN INDEPENDENCE}

Aвstract: This article intends to study the relationship between the indigenous peoples of Brazil and the independence of the country within the broad time frame of 1821-1850. The indigenous collective is considered here both as a passive and active agent in the process: a passive element in the royal legislation - from Pombal's time and during the Court's establishment in Rio, and during the imperial period-as much as it was in the parliamentary discussions; and an active element due to its involvement in the struggles for independence.

Key words: Brazil, indigenous people, Pombal's time, the Court in Rio, Independence, first reign, regency.

\section{NOTAS}

1 "se destinará en el Reino de Portugal y en Ultramar alguna casa, o casas, para habilitar misioneros destinados a la civilización de los indios y demás gentiles". Parecer presentado a las Cortes por la Comisión Eclesiástica el 8 de febrero de 1822 (DIARIO DAS CORTES..., 1822a).

2 Los primeros diputados brasileños, los correspondientes a Pernambuco, desembarcaron y prestaron juramento el 29 de agosto de 1821. Grao Pará fue el primer territorio de ultramar en adherir al sistema constitucional de la metrópoli portuguesa, el 1 de enero de 1821 y eligió tres representantes en las Cortes de Lisboa. Ese mismo día 10 de septiembre se produce la incorporación de los diputados de la provincia de Río de Janeiro.

3 El diputado Borges de Barros, natural de Salvador, formado en Coimbra, participante en el Senado de Cámara de Bahía en 1815 y más tarde, en tiempos imperiales, senador y vizconde de Pedra Branca, fue también poeta, autor de 
varias memorias técnicas sobre agricultura, entre otras una memoria sobre el cultivo del café y defensor en la Asamblea de los derechos civiles y políticos de las mujeres (SILVA NETO, 2003; BERBEL, 1999).

4 [Los directores] "marcarán ciertos días, y principalmente aquellos en que haya bautizos o matrimonios en la aldea, para las fiestas y danzas y alegrias decentes de que los índios sean más apasionados" (DIÁRIO DAS CORTES..., 1822b).

5 "procurarán [los directores] con todo desvelo y por intervención de indios civilizados en quien tuvieren mayor confianza, buscar a los errantes y salvajes, los cuales serán hospedados con afabilidad cuando vengan a las aldeas, comprándoles cuanto traigan a ellas y dándoles a cambio las mercancías que escogieren y de que habrá en la aldea la necesaria provisión y encomendándoseles cosas del país que precisen de manipulación, como pescado salado, para lo que se les dará sal y se les enseñará la forma de salar" (DIÁRIO DAS CORTES..., 1822b).

6 "El ciudadano que a su costa establezca en Brasil 35 familias extranjeras o doscientos índios de ambos sexos, será llamado amigo de la patria, su nombre será grabado en una lápida que para eso habrá em la principal sala de gobierno de la provincia y tendrá preferencia em todos los cargos honoríficos de ella" (DIÁRIO DAS CORTES..., 1822b).

7 "Los índios y gitanos o ya existentes en Brasil o que vayan para allá, solo podrán ser considerados como ciudadanos portugueses, cuando sean labradores de tierras propias o fabricantes convenientemente establecidos, debiendo em este último caso impetrar cartas de naturalización" (DIÁRIO DAS CORTES..., 1822b).

8 Diputado por la província de Pernambuco que se hizo conocido en Lisboa por ser el primero de los brasileños en tomar la palabra en la asamblea portuguesa y por su oposición al envío de tropas a la provincia que representaba. Eclesiástico, escritor y lider revolucionario en la insurrección de 1817; encarcelado en Bahía tras el aplastamiento de ésta fue autor de una historia de aquel movimiento (SILVA NETO, 2003). Fue uno de los diputados que huyeron de Lisboa hacia Londres clandestinamente en 1822 (BOEHRER, 1960).

9 El Diario das Cortes indicaba que su propuesta se había mandado unir a la antes ofrecida por el sr. Borges de Barros.

10 Octavo obispo de Pará. Presentado por el rey Joao VI para el episcopado de Belem en 1819, fue ordenado en abril e 1821 y tomó posesión inmediatamente después. Antes de ello, cuando era arcipreste y obispo electo, fue designado para presidir la Junta Provisional de la Provincia, la primera en constituirse en Brasil tras la adhesión del territorio a la revolución de Porto. Ya prelado, fue elegido diputado para representar a la provincia paraense en las Cortes de Lisboa, dónde firmó y juró la Constitución portuguesa (RAMOS, 1985; SILVA NETO, 2003). 
11 Según informaciones de F.R. Zany (apud ALARCON MEDEIROS, [200-a]), habría en el Alto Amazonas, parte de la provincia del Grao Pará, entre 24 y 30 mil habitantes "civilizados", incluyendo indios aldeados y más de cien mil indios "salvajes", mientras que Souza Franco, diputado por la provincia calculaba entre 30 y 35 mil "civilizados" - de los cuales cerca de 12 mil eran blancos y mamelucos - por 50 a 60 mil "salvajes"..

12 "Da junta do governo do Rio Grande do Norte datado de 30 de Janeiro, remettendo uma representação, que lhe dirigirão os indios, e mais moradores da villa de Extremoz, contra o seu Paroco José Ignacio de Brito, e informações da Camara respectiva. Mando-se remetter ao Governo" (DIARIO DAS CORTES..., 1822d).

13 Por ejemplo, para José Honorio Rodrigues (1963), el renovador de la historiografía más nacionalista de la independencia, José Bonifacio era: "un hombre que proponía providencias como la reforma agrária, el voto del analfabeto, la extinción inmediata del tráfico, la abolición gradual de la esclavitud, la incorporación del indio y que comandaba la lucha por la Independência, guerra mayor, por los combates y por el número de hombres que las de Bolívar y San Martín; y que, además, combatia empréstitos externos, defendía princípios de política externa como el anticolonialismo, la no-intervención, la autodeterminación, em fin, que formulo uma política propia e independiente al reconocer em las potencias europeas a los enemigos de entonces de la libertad nacional”. El mismo Rodrigues (1974) afirmaba que el pensamiento de José Bonifácio era caracterizadamente el "liberalismo conservador" o el "conservadurismo liberal".

14 La versión que llegó a las Cortes lisboetas se denominó Apontamentos para a civilizaçâo dos indios bárbaros do Reino do Brazil, fechada en Sao Paulo el 30 de ocubre de 1821. Aparece en el Diário das Cortes, sesión del 7 de marzo de 1822, presentado por el diputado António Carlos, hermano del autor.

15 Son citados por primera vez en las actas del 7 de marzo de 1822 como llegados y remitidos a la comisión de ultramar de las Cortes (DIARIO DAS CORTES..., 1822c). Las propuestas del que después se convertiría en político independentista son muy semejantes y paralelas en el tiempo a las presentadas por José Arouche de Toledo Rendón en torno a las aldeias indígenas. (vid. más abajo). Antes de su vuelta a Brasil en 1819, Bonifacio integró el grupo de lusitanos ilustrados liderado por Sousa Coutinho, conde de Linhares, cuyo principal objetivo era reformar y modernizar el Imperio portugués. El proyecto civilizatorio pretendía concretar en la parte americana de Portugal el sueño de un país europeo avanzado. Su propuesta formaba parte de una visión global del Imperio de la que Brasil era un parte. Y como tal la presentaba a la asamblea conjunta. La visión nacionalista solo llegaría más tarde, pero el texto serviría sin modificaciones (ANDRADA E SILVA, 2005), 
16 La representación sobre la esclavitud - "Representaçao sobre a escravidâo" - no llegó a ser presentada y se publicó durante su exilio en Francia en 1825.

17 Los sistemas de misiones habían convertido a los indios en "inútiles al estado". El prócer afirmaba por otro lado, probablemente sin datos que lo avalaran, que dos millones de indios habían muerto como consecuencia directa del sistema colonial, mientras que las leyes "emancipadoras" del reformista Pombal no supusieron mejoría alguna para los que lograron sobrevivir. Según el procer, muchas de las tribus, a la llegada de los portugueses, habían hecho ya notables progresos en agricultura, loza de barro, tejidos y obras de mano y, si no hubieran sido perseguidos y espantados, habrían progresado y no hubieran quedado estacionarios.

18 Especialmente los indios, de quienes Bonifacio escribía que eran "perezosos, pesados y voluptuosos" y por eso no está muy fuera de propósito lo que algunos dicen, "que entre el indio y el europeo de centro y norte Europa hay la misma diferencia que entre los indios y los monos grandes".

19 Para incentivar el matrimonio entre blancos e indios, llega incluso a pensar en ofrecer un premio en dinero, pues este tipo de unión era para él la mejor forma de civilizar a los salvajes e incorporar ese "tesoro" a la población de Brasil. El gran obstáculo a la civilización no eran los salvajes o bárbaros, sino el prejuicio, la ignorancia y el egoísmo de los portugueses colonialistas. La experiencia de Roma ya había demostrado como los pueblos bárbaros pueden llevar nuevas fuerzas a una civilización decadente (LOPES DE ARAUJO, 2006).

20 "Mezclemos a los negros con las indias y tendremos gente activa y robusta. Sacarán del padre la energía y de la madre la dulzura y el buen temperamento". Incluso, en apuntes añadidos posteriormente al texto inicial, proponía instituir un premio pecuniario a todo ciudadano blanco u hombre de color que se case con "india gentía".

21 Afirmaba que "Newton, si hubiera nacido entre los guaraníes, sería un bípedo más pisando sobre la superficie de la tierra, mientras que un guaraní criado por Newton tal vez ocuparía su lugar" (ANDRADA E SILVA, 2005).

22 El indio para él es perezoso porque tiene pocas o ninguna necesidad, dado que tiene todos los frutos de caza y pesca alrededor de sí y porque carece de la idea de propiedad. Por ello, cuando se colonice con indios, debe hacerse evitando que se establezcan en terrenos de mucha caza o pesca, porque volverían a entregarse en manos de la naturaleza. Con todo, era consciente de las dificultades que entrañaba la tarea de civilizar a los indios bravos, por sus costumbres de pueblos vagabundos, dados a continuas guerras y robos, porque no tienen frenos religiosos ni civiles, porque tienen miedo a morir de hambre si abandonan la 
caza y porque son conscientes de que si entran en el seno de la iglesia "serán forzados a dejar sus continuas bebidas, la poligamia en que viven ys los divorcios voluntarios y de aquí se deriva que las jóvenes casadas son las que mejor abrazan nuestra religión, porque así aseguran sus maridos y se libran de rivales". Pero también hay dificultades por parte de nuestra tradición de malos tratos. Por ello "debemos cambiar totalmente de maneras, conociendo primero lo que son los indios bravos para después encontrar los medios de convertirlos en lo 'que nos interesa que sean"' (ANDRADA E SILVA, 2005).

23 Según Bonifacio, los jesuitas, "con el evangelio en una mano y con presentes, paciencia y buenos modos en la otra, lo conseguían todo de los indios", mucho más que sus sucesores, los directores, tantas veces sus explotadores. "Es preciso pues imitar y perfeccionar los métodos de que usaban los jesuitas. Ellos, por medio de blandura y beneficios aldearon infinidad de indios bravos." Pero, tras el directorio pombalino, los indios debían (ANDRADA E SILVA, [200-]). De hecho, la rehabilitación del papel de los misioneros flotaba en el ambiente y no fue la suya la única propuesta de algo que se materializaría poco después en la legislación: en la sesión de las Cortes constituyentes del 4 de septiembre de 1822, el diputado Rebello expresaba: "la historia antigua y moderna no deja lugar a dudas de que la civilización de los salvajes se reserva exclusivamente a los ministros de la religión y que las providencias políticas son absolutamente inútiles para eso, debiendo el poder civil solo auxiliar a los misioneros" (DIÁRIO DAS CORTES..., 1822i).

24 Livro de Registro... (1957, p. 201-9). El estado de ordenación y clasificación de los papeles generados por las comisiones en el citado archivo - al menos a la altura de 2006 - impide cualquier intento de acercamiento a sus, por otra parte, seguro que interesantísimas discusiones.

25 El desarrollo del articulado establecería en el artículo uno, segunda sección, artículo 3 y en relación con el reparto de los impuestos directos: "Los representantes y los impuestos directos se prorratearán entre los distintos Estados que formen parte de esta Unión, de acuerdo con su población respectiva, la cual se determinará sumando al número total de personas libres, inclusive las obligadas a prestar servicios durante cierto término de años y 'excluyendo a los indios no sujetos al pago de contribuciones', las tres quintas partes de todas las personas restantes", mientras que la octava sección, entre las atribuciones del Congreso incluía en su artículo 3: "Reglamentar el comercio con las naciones extranjeras, entre los diferentes Estados ' $y$ con las tribus indias".

26 Asi lo reconocía la célebre decisión de la Corte Suprema conocida como Worcester versus Georgia que reconocía el status de naciones semisoberanas y autónomas bajo protección federal. En cualquier caso, hay que decir que en toda la política 
norteamericana hacia el indio subyacía siempre la idea de que los indios eran seres salvajes y crueles a los que era imperativo "civilizar".

27 Capítulo II. De los españoles. Artículo 5, en Constitución Política de la Monarquía española promulgada en Cádiz a 19 de marzo de 1812 (2000).

28 Lo que diferenciaba al texto gaditano de otros textos contemporáneos, entre ellos los de Portugal y Brasil, que vinculaban la ciudadanía a la propiedad y la fiscalidad. Aquí se usó el concepto de ciudadano equiparado a "vecino".

29 En este capítulo, Marchena efectúa reflexiones sobre las repercusiones que el texto tuvo entre las poblaciones indígenas. Cfr. también Clavero (2000) en el mismo volumen y desde luego el magistral capítulo de José María Portillo Valdés (2006).

30 Titilo VI. Del gobierno interior de las provincias y los pueblos, Capítulo II, Del gobierno político de las provincias y de las diputaciones provinciales, Artículo 335, décimo: Las diputaciones de las provincias de ultramar velarán sobre la economía, orden y progresos de ls misiones para la conversión de los indios infieles, cuyos encargados les darán razón de sus operaciones en este ramo, para que se eviten los abusos, todo lo que las diputaciones pondrán en noticia del gobierno.

31 Bahiano, periodista combativo, filósofo y médico, licenciado en Coimbra, gran orador, liberal radical, miembro de la famosa Logia "Cavaleiros da Luz" de Salvador, revolucionario participante tanto de la revolución bahiana de 1798 como de la pernambucana de 1817, fue electo diputado por Bahía a las Cortes constituyentes de Lisboa, de dónde volvió a Brasil para ser elegido a la Asamblea Constituyente del Imperio. Mantuvo una frontal oposición al emperador, lo que le valió sufrir una fuerte represión. Liberal radical, fue también periodista y publicó varios periódicos. Fue uno de los representantes brasileños que huyó clandestinamente de Lisboa en 1822 (BOEHRER, 1958).

32 Junto con el diagnóstico, Zany presentó al presidente de la provincia, Barâo de Bagé un plan nuevo plan de civilización de los indios, que éste envió al gobierno imperial sin que produjera efecto alguno ni respuesta.

33 El profesor George C. Boehrer, que dio a luz en 1963 la mejor edición crítica hasta entonces de las obras de José Bonifacio de Andrada (BOEHRER, 1958), estudió también las diferentes versiones del proyecto del prócer, entre ellas las dos enviadas a las sucesivas asambleas constitucionales de Portugal primero y Brasil después y concluyó que sus diferencias no eran demasiado significativas (BOEHRER, 1960).

34 Su versión brasileña se tituló Apontamentos para a civilizaçao dos indios bravos do Império do Brasil. 
35 La práctica de la distribución de niños era corriente en la captura de grupos indígenas en conflicto con la población blanca y lo seguiría siendo todavía durante una buena parte del periodo imperial.

36 "Las familias indias, que forman la parte más preciosa de la población, acosadas y perseguidas andan dispersas y huidas para las selvas que antes habían dejado. Por todas partes se practica con ellos aquella atrocidad y perfidia que practicaron con estos inocentes indios los primeros conquistadores del Nuevo Mundo. [...] Los indios hoy [están] dispersos y errantes por la bárbara persecución que sufrieron bajo los últimos gobernadores de la comarca" (ALARCON MEDEIROS, [200-a], [200-b]). D. Romualdo, sobrino de D. Romualdo de Souza Coelho, quien presentaba una moción a las Cortes de Lisboa en torno a la cuestión india, eclesiástico y luego obispo de Bahía, representó a Pará en la primera Asamblea reunida después del otorgamiento de la Constitución de 1824. Vid. Ramos (1985) e Silva Neto (2003).

37 Sobre las constituciones del inicio del imperio, vid. Berbel (2008).

38 Sobre la consideración histórica y la actual del tiempo de la independencia, vid. Jancsó (2005).

39 En todo lo que se refiere a la participación indígena en los movimientos pernambucanos seguimos a este profesor de la Universidad Federal de Pernambuco, máximo conocedor de estas actuaciones. Vid. también Pires (2005).

40 Carvalho (1998) que los caciques fueron gradualmente ensombrecidos por los Capitaes-Mores y otros oficiales de milicias o bien se volvieron ellos mismos grados de esa nueva jerarquía.

41 Un testigo presencial, el residente francés Tollenare (1905), describía así la presencia de los indios en el ejército realista triunfante: "[en Recife] se suspiraba por la llegada del ejército real; éste, victorioso en Serinhâem, avanzaba tan lentamente que solo el día 23 aparecieron algunos de sus cuerpos de caballería. En la tarde del 22 llegaron bandas de indios armados de flechas; le dimos limosnas, pero no podía contarse con ellos para mantener el orden. Solo la presencia posterior del mariscal Mello, cuyo ejército se había formado en Bahia, restableció la tranquilidad. [tras el fin de la revolución y la entrada realista en Recife], los indios mostraron mucha dedicación por el rey. Nos enseñan su habilidad para manejar las flechas a cambio de algunos vintens. Pronto mandaron volver a sus lugares de origen a los indios reclutados con lo que volvió la tranquilidad, pues estas tropas irregulares cometieron desórdenes en los ingenios azucareros".

42 Frei Caneca, el monje revolucionario pernambucano explicaba que la falta de entusiasmo de las órdenes regulares a la causa del Brasil obedecía a los votos que hacían de fidelidad al rey de Portugal.

43 A lo largo de los siglos, los indios adoptaron estrategias muy diversas de acción

Hist.R., Goiânia, v. 16, n. 1, p. 81-131, jan./jun. 2011 
y reacción en el tiempo y el espacio en su relación con los europeos: conflictoguerra/negociación-alianza.

44 Tales estructuras fueron aprovechadas tanto en ocasiones para la insurrección como para el alistamiento en las tropas imperiales, muchas veces para la lucha contra la rebeldía de otros indios o de negros alzados, vid. Dantas e Carvalho (1992).

45 El nombre derivaba del origen social de sus componentes mayoritarios, los "cabanos", habitantes de las casas de paja, las "cabanas". Sobre la cabanagem, vid. Chiavenato (1984) y Alarcon Medeiros ([200-b]), que incluye un estado de la cuestión de los estudios históricos sobre el movimiento.

46 Bezerra da Silveira, en Cabanagem, uma luta perdida (1994), sustenta la idea de que la cabanagem fue una lucha de la población amazónica, en su inmensa mayoría indios puros y mestizos, por el derecho al acceso a la tierra. Hurley (1936) escribía que uno de los detonantes de la explosión popular cabana radicó en la extrema explotación a que el poder colonial portugués sometió a los indios y que ésta situación fue la que originó el fuerte antilusitanismo del movimiento.

47 Los mura vivían en el Amazonas medio y fueron siempre muy perseguidos por el poder colonial, que los acusaba de vivir de la piratería en los ríos. Los mawe lideraron la revolución en Parintins y en Tupinambara.

48 La represión de los vencedores no se limitó a esas formas sangrientas. Los supervivientes fueron encuadrados en la ley de 25 de abril de 1538 que establecía en Pará el Cuerpo de Trabajadores, una forma de reclutamiento de mano de obra coercitivo que daba a la autoridad el derecho a hacer la distribución de la fuerza disponible de acuedo con sus intereses para las obras públicas y el servicio de particulares. El cuerpo de trabajadores, formado por individuos no blancos considerados "libres", de carácter abiertamente racista permaneció en vigor hasta 1870 y fue copiado en Maranhao con el nombre de "Corpo de Trabalhadores Indios", vid. Ramos (2004).

49 En una discusión que tuvo lugar en 1839en el seno de la Asamblea del Imperio sí que apareció tangencialmente la cuestión de la representación india. Discutiendo en torno a la división de la provincia de Grao Pará, el diputado Henriques de Resende afirmaba que no había los cien mil indios "salvajes" que se pretendía que había y que además, si los indios entraran en el cálculo, "entonces sería necesario que hubiera un diputado indios y que esos indios salvajes hiciesen su elección, porque de lo contrario no estarían representados". El igualmente diputado Souza Franco le respondía que "él [Resende] sostenía que los indios no debían entrar en cálculo, porque tenían derechos y que sus diputados no serían tales diputados. Supongo que el señor diputado debe recordar que los indos tienen derechos como cualquier otro habitante del imperio y que los civiles le están asegurados por diversas leyes y puestos [los indios]bajo la tutela del juez de huérfanos. Si 
no están aun en el caso de contribuir a la elección de los diputados de provincia, no por eso dejan de tener el derecho a ser representados" Vid. Alarcon Medeiros ([200-b]).

50 En 1826, el gobierno imperial enviaba una encuesta a cada presidente de provincia a fin de conocer la situación de los indios, la localización de las tierras más propicias para erigir aldeamentos y la razón del fracaso de las medidas de gobierno para la civilización de los indígenas hasta entonces, así como propuestas para la elaboración de un "Plan General de civilización para los indios", que nunca se formuló. En ausencia de una directriz general indigenista, en el tiempo del primer emperador la política fue elaborada por las provincias.

51 Colocados bajo la jurisdicción del "juiz dos órfãos". Sobre su situación en el tiempo imperial, vid. Carneiro da Cunha (1992a).

52 En 1821, por ejemplo, cinco naciones indígenas de los márgenes del Tocantins reclamaron legalmente en el tiempo del proceso constituyente por ser tratadas "como esclavos de Etiopía, robándoles sus tierras que fueron concedidas por Dios a sus legítimos abuelos" (KARASCH, 1992).

53 Carvalho (1998) cita como significativo el caso de los indios de Barreiros Pernambuco -, que perdieron las tierras que habían recibido como pago a su colaboración en la lucha contra el quilombo de Palmares en el siglo XVII. Dos siglos después, esa circunstancia ya no contaba para defendérselas.

54 Sobre la situación de los indígenas y la política imperial en las décadas siguientes a la independencia, vid. Gomes (1988), Alarcón Medeiros ([200-b]), Ramos (2004), Calavia Saez (2004), Barros Laraia (1993) e Carneiro da Cunha (1992a).

55 Von Martius era un botânico que recorrió partes de Brasil em 1819 y que defendia posiciones muy pesimistas respecto a la capacidad de "civilizarse" de los índios (CARNEIRO DA CUNHA, 1992d).

\section{REFERENCES}

"A JUSTIÇA NO AMAZONAS COLONIAL. O Poder judiciario na historia do Amazonas", en www.tjam.jus.br/index.php?option=com_docman\&task, acceso el 7-06-2008

ALARCON MEDEIROS, V.B. Incompreensível colosso. A Amazonia no início do Segundo Reinado (1840-1850), Tesis de doctorado presentada en la Universidad de Barcelona bajo la dirección de la Dra. Pilar García Jordán en 2006. En http://www. tesisenred.nt/0721105-124851. Acceso em 27-11-08.

ALENCAR, J. de. Como e porque sou romancista. In: ALENCAR, J. de. Obra com- 
pleta. Rio de Janeiro: Aguilar, 1965.

ANAES DO PARLAMENTO BRAZILEIRO. Assemblea Constituinte 1823, 18 jun. 1823.

ANAES DO PARLAMENTO BRASILEIRO. Cámara dos Sres Diputados, 1826.

ANAES DO PARLAMENTO BRAZILEIRO. Assemblea Constituinte 1823, v. V. 23 sep./02 oct. 1823. Disponível em: <http://imagem.camara.gov.br/dc_20a. asp? selCodColecaoCsv>. Acesso em: 23-12-2008.

ANDRADA, J. B. de. Introducción a projetos para o Brasil, Edición de DOLHNIKOFF, Miriam, São Paulo: Cia. das Letras, 2005.

ANDRADA E SILVA, J. B. de. Projetos para o Brasil. In: DOLHNIKOFF, Miriam (Org.). São Paulo: Cia. das Letras, 2005.

APONTAMENTOS PARA A CIVILIZAÇÃO dos índios bárbaros do Reino do Brazil. Diário das Cortes, 07 mar. 1822.

ARQUIVO DE ITAMARATY. Pedido de repressão a pilhagens dos indígenas de Santa Clara de Francisco Dionisio Fortes. Diversos documentos avulsos, Rio de Janeiro, lata 203, maço 03, pasta 06, 1817.

BARROS LARAIA, R. Los índios de Brasil. 3. ed. Madrid: Mapfre, 1993.

BERBEL, M. R. A constituição espanhola no mundo luso-americano (1820-1823). Revista de Indias, v. LXVIII, n. 242, p. 225-254, 2008.

BERBEL, M. R. A nação como artefato. Diputados do Brasil nas Cortes portuguesas, 1821-1822. São Paulo: Hucitec, 1999.

BEZERRA DA SILVEIRA, I. Cabanagem, uma luta perdida. Belém: Ed. da Secretaria de Estado de Cultura, 1994.

BOEHRER, C. G. A. Obras científicas, políticas e sociais de José Bonifacio. Santos, 1963.

BOEHRER, C. G. A. Variant Version of Jose Bonifacio's Plan for the civilization of the Brazilian Indians. The Americas, v. XIV, p. 3, jan. 1958.

BOEHRER, C. G. A. The flight of the brazilian deputies from the Cortes Generais of Lisbon, 1822. The Hispanic American Historical Review, v. 40, n. 4, p. 497-512, nov. 1960.

CALAVIA SAEZ, O. Indios, territorio y nación en Brasil. Antropología em primeira mao, Florianópolis, Univ. Fed. de Santa Catarina, 2004. Disponível em: http://www. antropologia.ufsc.br. Acesso em: 19-05-2008.

CARNEIRO DA CUNHA, M. Definiçoes de indios e comunidades indígenas nos texos legais. In: SANTOS, Silvio Coelho dos (Org.). Sociedades indígenas e o directo: uma questao de directos humanos. Florianópolis: Ed. da UFSC-CNPq, 1985. 
CARNEIRO DA CUNHA, M. Historia dos indios no Brasil. São Paulo: Cia. das Letras, 1992a.

CARNEIRO DA CUNHA, M. Introdução a uma historia indígena. In: CARNEIRO DA CUNHA, M. História dos índios no Brasil. São Paulo: Cia. das Letras, 1992b.

CARNEIRO DA CUNHA, M. (Org.). Legislação indigenista no século XIX (18081889). Sâo Paulo: Edusp-Comissão Pro Indio, 1992c.

CARNEIRO DA CUNHA, M. Política indigenista no século XIX. In: CARNEIRO DA CUNHA, M. História dos índios do Brasil. São Paulo: Cia. das Letras, 1992d.

CARVALHO, M. J. M. de. Cavalcantis e cavalgados: a formaçao das alianças politicas em Pernambuco, 1817-1824. Revista Brasileira de Historia, v. 18, n. 36, São Paulo, 1998.

CARVALHO, M. J. M. de. Os índios e o ciclo das insurreiçoes liberais em Pernambuco (1817-1848): ideologías e resistencia. Indios do Nordeste: temas e problemas. Maceió: Ed. da Universidade Federal de Alagoas, 2002.

CHIAVENATO, J. J. Cabanagem, o povo no poder. São Paulo: Brasiliense, 1984.

CLAVERO, B. Cádiz como constitución. Constitución Política de la Monarquía española promulgada en Cadiz a 19 de marzo de 1812, Sevilla, Ayto de Cádiz, Casino Gaditano, Univ. de Cádiz, Fundación El Monte, 2000.

COMISIÓN ECLESIÁSTICA El 08 de febrero de 1822. Diario das Cortes Constituintes de la citada fecha.

CONSTITUCIÓN POLÍTICA de la Monarquía Española. Promulgada en Cádiz, 19 mar. 1812, 2000.

CONSTITUCIÓN PORTUGUESA de 23 de setembro de 1822. Disponível em: $<$ http://www.cervantesvirtual.com/>. Acesso em: 12-07-2008.

CORREIA DE ANDRADE, M. A guerra dos cabanos. Rio de Janeiro: Conquista, 1965. CORREIO BRASILIENSE, 29 sept. 1822. p. 371-387.

DANTAS, B. G.; CARVALHO, J. A. Os povos indígenas no nordeste brasileiro. In: CARNEIRO DA CUNHA, M. Historia dos índios no Brasil São Paulo: Cia. das Letras, 1992.

DEBRET, J. B. Voyage pictoresque et historique au Brésil, ou sejour d'un artiste français au Bresil. Paris: Firmin Didot, 1834.

DIARIO DAS CORTES CONSTITUÍNTES, 18 mayo 1821a.

DIÁRIO DAS CORTES Constituintes, $18 \mathrm{dez} .1821 \mathrm{~b}$.

DIÁRIO DAS CORTES Constituintes, 8 de febrero de 1822a.

DIÁRIO DAS CORTES Constituintes, 7 de marzo de 1822 b. 
DIÁRIO DAS CORTES Constituintes, 18 mar. 1822c.

DIÁRIO DAS CORTES Constituintes, 09 abr. 1822d.

DIÁRIO DAS CORTES Constituintes, 29 abr. 1822e.

DIÁRIO DAS CORTES Constituintes, 06 mayo $1822 \mathrm{f}$.

DIÁRIO DAS CORTES Constituintes, $1^{\circ}$ jul. 1822g.

DIÁRIO DAS CORTES Constituintes, 03 jul. 1822h.

DIÁRIO DAS CORTES Constituintes, 04 sep. 1822i.

DIÁRIO DAS CORTES Constituintes, 13 ago. 1822j.

DIÁRIO DAS CORTES Constituintes, 26 ago. 1822k.

DIÁRIO DAS CORTES Constituintes, 14 sep. 18221.

DOMÍNGUES, A. Quando os indios eram vasalos. Colonização e relações de poder no norte do Brasil na segunda metade do século XVIII. Lisboa: Comissâo Nacional para as Commemoraçôes dos Descobrimentos Portugueses, 2000.

FABRE, A. Diccionario etnolingüístico y guía bibliográfica de los pueblos indígenas sudamericanos. Disponível em: <http://butler.cc.tut.fi/ fabre/BookInternetVersio/ Alkusivu.html>. Acesso em: 15-10- 2007.

GOMES, M. P. Os indios e o Brasil. Petrópolis: Vozes, 1988,

HURLEY, J. A cabanagem. Belém: Livraria Clasica, 1936.

JANCSÓ, I. Independência: história e historiografia. São Paulo: Hucitec, 2005.

KARASCH, M. Catequese e cativeiro. Política indigenista em Goias: 1780-1889. In: CARNEIRO DA CUNHA, M. Historia dos índios do Brasil. São Paulo: Companhia das Letras, 1992.

LIMA, O. Don Joao VI no Brasil. Rio de Janeiro: Topbooks, 1996.

LIVRO DE REGISTRO, Comissao de Ultramar, Papeis das Cortes Gerais, Arquivo da Assembleia Nacional, Sala 1, Estante 1, n. 2602. In: BOEHRER, G. C. A. Some brazilian proposals to the Cortes Gerais, 1821-23, on the indian problem. International Colloquium on Luso-Brasilian Studies, v. 3, p. 201-209, 1957.

LOPES DA SILVA, A. Dois séculos e meio de história xavante. In: CARNEIRO DA CUNHA M., Historia dos índios do Brasil. São Paulo: Companhia das Letras, 1992.

LOPES DE ARAUJO, V. Como transformar portugueses em brasileiros: Jose Bonifacio de Andrada e Silva. Revista Intellectus, Ano05, v. 1, 2006.

LUCCOCK, J. Notes on Rio de Janeiro and the southern parts of Brazil. Taken during a residence of ten years in that country, from 1808 to 1818. In: WILCKEN, P. Imperio a deriva. A corte portuguesa no Río de Janeiro, 1808-1821. Rio de Janeiro: 
Objetiva, 2005.

MARCHENA FERNÁNDEZ, J. La Constitución de Cádiz y el ocaso del sistema colonial español en América. Constitución Política de la Monarquía española promulgada en Cadiz a 19 de marzo de 1812, Sevilla, Ayto de Cádiz, Casino Gaditano, Univ. de Cádiz, Fundación El Monte, 2000.

MIRANDA DIAS, C. M. Balaiada: a guerrilha sertaneja. Estudos, Sociedade e Agricultura, v. 5, p. 73-88, nov. 1995.

MOREIRA NETO, C. A. Os indios e a ordem imperial. Brasilia: Ed. da Funai, 2005. MOTA, L. T. O Instituto Histórico e Geográfico Brasileiro e as propostas de integraçao das comunidades indígenas no Estado Nacional. In: II ${ }^{a}$ REUNIÓN DE ANTROPOLOGÍA DEL MERCOSUR: FRONTERAS CULTURALES Y CIUDADANÍA- GT27 ETNICIDADES Y ESTADOS NACIONALES, Piriapolis (Uruguay), 11 a 14 del 11 de 1997. Anais... Dialogos, v. 2. Disponível em: red:http://www.dhi. uem.br/publicaçoes dhi/dialogos. Acesso em: 14-08-2008

PARAISO, M. H. B. Os botocudos e sua trajetoria histórica. In: CARNEIRO DA CUNHA, M. Os indios do Brasil. São Paulo: Cia. das Letras, 1992.

PERRONE-MOISES, B. Indios livres e indios escravos. Os princípios da legislação indigenista do período colonial (séculos XVI a XVIII). In: CARNEIRO DA CUNHA, M. História dos índios do Brasil. São Paulo: Cia. das Letras, 1992.

PIRES, M. I. Resistencia indígena nos sertões nordestinos no pós-conquista territorial. In: SIMPÓSIO TEMÁTICO GUERRAS E ALIANÇAS NA HISTÓRIA DOS ÍNDIOS, Londrina, 17 a 22 de julho de 2005.

PORTILLO VALDÉS, J. M. Los indios calzados: la mayoría en minoría. Crisis atlántica. Autonomía e independencia en la crisis de la monarquía hispana. Madrid: Marcial Pons, 2006.

PRADO JUNIOR, C. Evoluçao política do Brasil e outros estudos. São Paulo: Brasiliense, 1979.

RAMOS, A. G. Cronología eclesiástica do Pará. Belém: Falângola, 1985.

RAMOS, A. R. F. A escravidão do indígena entre o mito e novas perspetivas de debates. Revista de Estudos e Pesquisas, Brasilia, v. I, n. 1, p. 241-265, jul. 2004.

REIS, A. C. F. O Amazonas nos primeiros tempos do Imperio. Revista do Instituto Historico e Geografico Brasileiro, v. 316, p. 116-123, jul./set. 1977.

RODRÍGUES, J. H. A Assembléia Constituinte de 1823. Petrópolis: Vozes, 1974.

RODRIGUES, J. H. O pensamento político e social de José Bonifácio. In: FALCÃO, Edgar Cerqueira de (Org.). Obras científicas, políticas e sociais de José Bonifácio. Santos, 1963. V. 2. 
SILVA, A. Delgado da. Legislaçao portuguesa desde a última compilaçao das ordenações. Legislação de 1750 a 1762. Lisboa: Maigrense, 1830. Disponível em: <http:// www.iuslusitaniae.fcsh.unl.pt>. Acesso em: 03-11-2007.

SILVA, T. G. da. Junta de civilização e conquista dos índios e navegação do rio Doce. In: MONTEIRO, J.; CELESTINO DE ALMEIDA, M. R.; PACHECO DE OLIVEIRA, J. Guerras e alianças na história dos índios: perspectivas interdisciplinares. In: XXIII SYMPOSIO NACIONAL DE HISTORIA (ANPUH), Londrina, 17-22 jul. 2005. Anais, 2005.

SILVA NETO, C. P. da. A construção da democracia. Brasília: Centro de Documentação e Informação, 2003. Disponível em: <http://www.camara.gov.br/internet/ infdoc/publicaçoes/.../construçao1.pdf>. Acesso em: 03-11-2007.

SPOSITO, F. A liberdade dos indígenas no império do Brasil. Motivações e impasses presentes no Parlamento Brasileiro para a revogação das guerras justas contra os 'indios selvagens' entre 1830 e 1831. In: XIX ENCONTRO REGIONAL DE HISTORIA: PODER, VIOLÊNCIA E EXCLUSÃO, São Paulo, Anpuh/USP, 08 a 12 set. 2008. Anais..., 2008. (CD).

TOLLENARE, L. F. Notas dominicaês, tomadas durante uma residencia em Portugal e no Brasil nos anos 1816, 1817 e 1818: parte relativa a Pernambuco. Jornal do Recife, Recife, 1905.

TREECE, D. Exilados, aliados, rebeldes. O movimento indianista, a politica indigenista e o Estado-Naçâo Imperial. São Paulo: Edusp, 2008.

VON MARTIUS, K. F. Como se debe escrever a historia do Brasil. Revista do Instituto Histórico e Geográfico do Brasil, Rio de Janeiro, v. 6, n. 24, 1845.

ZACHEO, M. P. S. Discurso do arguelles da provincia de Maranhao a S. Magestade Nacional e Real em Cortes Gerais sobre a opinião publica, liberdade civil e comercio de escravatura. Lisboa: João Nunes Esteves, 1822. In: CHECHE GALVES, M. Homens de cor no processo de independência da província de Maranhão. In: XXIV SYMPOSIO NACIONAL DE HISTORIA, 2007, ASSOCIAÇÃO NACIONAL DE HISTORIA, 2007. Anais..., 2007. 